Journal for ImmunoTherapy of Cancer

\title{
Lack of myeloid cell infiltration as an acquired resistance strategy to immunotherapy
}

Elham Beyranvand Nejad (D) , ${ }^{1}$ Camilla Labrie, ${ }^{1}$ Ziena Abdulrahman (D) ,' Marit $\mathrm{J}$ van Elsas, ${ }^{1}$ Eva Rademaker, ${ }^{2}$ Jan Willem Kleinovink (D) , ${ }^{1}$ Tetje C van der Sluis, ${ }^{3}$ Suzanne van Duikeren, ${ }^{3}$ Amina F A.S Teunisse, ${ }^{4}$ Aart G Jochemsen, ${ }^{4}$ Jan Oosting, ${ }^{2}$ Noel F C C de Miranda (D) ${ }^{2}$ Thorbald Van Hall (D) , ${ }^{1}$ Ramon Arens (D) , ${ }^{3}$ Sjoerd H van der Burg (D) ${ }^{1}$
To cite: Beyranvand Nejad E, Labrie C, Abdulrahman Z, et al. Lack of myeloid cell infiltration as an acquired resistance strategy to immunotherapy. Journal for ImmunoTherapy of Cancer 2020;8:e001326. doi:10.1136/jitc-2020-001326

$\mathrm{CL}$ and ZA contributed equally.

Accepted 06 August 2020
Check for updates

(c) Author(s) (or their employer(s)) 2020. Re-use permitted under CC BY-NC. No commercial re-use. See rights and permissions. Published by BMJ.

${ }^{1}$ Oncode institute, Medical Oncology, Leiden University Medical Center, Leiden, The Netherlands

${ }^{2}$ Pathology, Leiden University Medical Center, Leiden, The Netherlands

${ }^{3}$ Immunohematology and Bloodtransfusion, Leiden Universitair Medisch Centrum, Leiden, The Netherlands

${ }^{4}$ Cell and Chemical Biology, Leiden University Medical Center, Leiden, The Netherlands

Correspondence to

Professor Sjoerd $\mathrm{H}$ van der Burg; shvdburg@lumc.nl

\section{ABSTRACT}

Background Immunotherapy of cancer is successful but tumor regression often is incomplete and followed by escape. Understanding the mechanisms underlying this acquired resistance will aid the development of more effective treatments.

Methods We exploited a mouse model where tumorspecific therapeutic vaccination results in tumor regression, followed by local recurrence and resistance. In depth studies on systemic, local and tumor intrinsic changes were performed with flow and mass cytometry, immunohistochemistry, transcriptomics and several perturbation studies with inhibitors or agonistic antibodies in mice. Main findings were recapitulated in vaccinated patients.

Results Full tumor regression and cure of tumor-bearing mice is dependent on the magnitude of the vaccineinduced T-cell response. Recurrence of tumors did not involve classical immune escape mechanisms, such as antigen-presentation alterations, immune checkpoint expression, resistance to killing or local immune suppression. However, the recurrent tumors displayed a changed transcriptome with alterations in $\mathrm{p} 53$, tumor necrosis factor- $\alpha$ and transforming growth factor- $\beta$ signaling pathways and they became immunologically cold. Remarkably, ex vivo cell-sorted recurrent tumors, directly reinjected in naïve hosts retained their resistance to vaccination despite a strong infiltration with tumorspecific $\mathrm{CD}^{+} \mathrm{T}$ cells, similar to that of vaccine-responsive tumors. The influx of inflammatory mature myeloid effector cells in the resistant tumors, however, was impaired and this turned out to be the underlying mechanisms as restoration of inflammatory myeloid cell infiltration reinstated the sensitivity of these refractory tumors to vaccination. Notably, impaired myeloid cell infiltration after vaccination was also associated with vaccine resistance in patients.

Conclusion An immunotherapy-induced disability of tumor cells to attract innate myeloid effector cells formed a major mechanism underlying immune escape and acquired resistance. These data not only stresses the importance of myeloid effector cells during immunotherapy but also demands for new studies to harness their tumoricidal activities.

\section{BACKGROUND}

Immunotherapy has become clinically effective in multiple cancers. Blockade of the immune inhibitory checkpoints cytotoxic T-lymphocyte-associated protein 4 (CTLA-4) and programmed cell death protein 1 (PD-1) as well as adoptive transfer of (genetically modified) $\mathrm{T}$ cells are the successful examples. In addition, therapeutic vaccines targeting tumor-specific antigens start to show clinical benefit, especially when used in combination with other therapies. Despite the many patients with complete responses, the majority of clinically responding patients show partial tumor regressions after immunotherapy. ${ }^{1-7}$ Several primary and acquired resistance mechanisms, including low tumorspecific antigen load, antigen processing and presentation defects, T-cell exclusion, and local immune suppression by suppressive myeloid cell populations, regulatory $\mathrm{T}$ cells and coinhibitory molecule expression, allow tumors to become therapy resistant, limiting the clinical efficacy of the immunotherapeutic approaches used. ${ }^{8}$

The concept of immune editing dictates that a non-curative immune response eventually drives tumor immune escape. ${ }^{9}$ Unfortunately, most of the tumor models in which systemic immunotherapy is tested show tumor growth delay but not actual tumor regression and by this deviate from what is observed in the clinic. We have shown that under optimal conditions, therapeutic vaccination with the human papillomavirus (HPV16) E7 ${ }_{43-77}$ synthetic long peptide (SLP) and the toll-like receptor 9 agonist $\mathrm{CpG}$ results in full tumor regression and cure of all mice with an established TC-1 tumor. However, under suboptimal vaccine conditions TC-1 tumors do regress but after 
a period regrow, ${ }^{10}{ }^{11}$ hereby mimicking non-curative partial clinical responses.

To understand the mechanisms driving immune escape after non-curative immunotherapy, we performed a detailed analysis of extrinsic and intrinsic mechanisms that may foster the development of therapy-refractory tumors. Our data indicate that resistance to T-cell-based immunotherapy not necessarily resides in pathways directly involving interaction between $\mathrm{T}$ cells and tumor cells, but can also be the result of an impaired co-infiltration with innate immune cells. This stresses the need for a reappraisal of tumor-infiltrating innate immune cells during immunotherapy focusing not only on their potential immune suppressive roles but also on their tumoricidal and phagocytic activities.

\section{METHODS \\ Mice}

C57BL/6 mice were purchased from Charles River Laboratories (L'Arbresle, France). All mice were $6-8$ weeks old at the beginning of the experiment. Mice were housed in individually-ventilated cages under specific pathogenfree conditions. All animal experiments were approved and executed in compliance with the guidelines of Dutch and European committees.

\section{Tumor challenge and treatments}

The tumor cell line TC-1 was generated by retroviral transduction of C57BL/6 lung epithelial cells with the HPV16 E6/E7 and c-H-ras oncogenes. ${ }^{12}$ Mice were inoculated subcutaneously with $10^{5}$ TC-1 tumor cells in 200 $\mu \mathrm{L}$ phosphate buffered saline (PBS) containing $0.2 \%$ bovine serum albumin (BSA) on day 0 . Tumor size (horizontal dimension $\times$ vertical dimension) was measured twice a week using a caliper. On day 7 post-tumor injection, mice were divided into groups with comparable tumor sizes. On day 8 and 22 post-tumor challenge, mice were vaccinated with SLP vaccine subcutaneously in the contralateral flank (suboptimal setting: all figures) or tail base (optimal setting). SLP vaccine contains $100 \mu \mathrm{g}$ HPV16 E7 ${ }_{43-63}$ (GQAEPDRAHYNIVTFCCKCDS) covering both Th epitope and the CTL epitope with $20 \mu \mathrm{g}$ CpG (ODN1826, InvivoGen) dissolved in $200 \mu \mathrm{L}$ (flank) or $50 \mu \mathrm{L}$ (tail base) PBS and emulsified with incomplete Freunds adjuvants (flank). Cisplatin is administered at 10 $\mathrm{mg} / \mathrm{kg}$ in $300 \mu \mathrm{L}$ saline intraperitoneally (i.p.). Mice were routinely weighed 2-3 times/week. To deplete myeloid cells, CSF1R inhibitor PLX3397 or control was incorporated into chow at $290 \mathrm{mg} / \mathrm{kg}$, resulting in a daily delivery of $\sim 45 \mathrm{mg} / \mathrm{kg}$ and was obtained from Plexxikon. Mice were euthanized when tumor size reached $>2000 \mathrm{~mm}^{2}$ or when mice lost over $20 \%$ of total body weight. For i.p. antibodies treatments, anti-PD-1 clone RMP1-14 (150-200

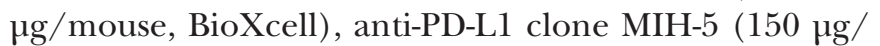
mouse, purified in-house), OX-40 clone OX86 (150 $\mathrm{\mu g} /$ mouse, Bioceros) and 4-1BB clone 3H3 (150 $\mu \mathrm{g} / \mathrm{mouse}$, purified in-house), CXCR3 clone CXCR3-173 (200 $\mu \mathrm{g}$ / mouse i.p every 3 days, BioXcell), transforming growth factor- $\beta$ (TGF $\beta$ ) neutralizing clone 1D11.16.8 and interleukin 6 (IL-6) blocking clone MP5-20F3 (200 $\mu \mathrm{g} / \mathrm{mouse}$, every 3-4 days i.p. and intravenously, respectively, BioXcell). Antibodies were administered as indicated in figure legends. RG7112 (Chemgood, USA) $100 \mathrm{mg} / \mathrm{kg}$ daily by oral suspension in $200 \mu \mathrm{L}$ of $0.5 \mathrm{w} / \mathrm{v} \%$ methyl cellulose 400 (Wako Pure Chemical Industries; Osaka, Japan).

\section{Flow cytometric analysis of splenic and intratumoral immune cells}

Tumors were collected after transcardial perfusion and incubated with Liberase (Roche) in IMDM for $15 \mathrm{~min}$ at $37^{\circ} \mathrm{C}$. Spleen and lymph nodes were incubated with 0.02 $\mathrm{mg} / \mathrm{mL}$ DNAse and $1 \mathrm{mg} / \mathrm{mL}$ collagenase for $10 \mathrm{~min}$ at room temperature. Single-cell suspensions were prepared by mincing spleen and tumor pieces through a $70 \mu \mathrm{m}$ cell strainer (BD Biosciences). Cells were resuspended in staining buffer $(\mathrm{PBS}+2 \%$ fetal calf serum $+0.05 \%$ sodium azide) and incubated with various fluorescently labeled antibodies against: CD11b (clone M1/70), CD11c (clone N418), CD45.2 (clone 104), F4/80 (clone BM8), Ly6C (clone HK1.4), Ly6G (clone 1A8), EGR2 (clone erongr2) and iNOS (clone CXNFT). Antibodies were obtained from eBioscience and Biolegend. APC labelled- $\mathrm{H}-2 \mathrm{D}^{\mathrm{b}}$ tetramers containing HPV16 $\mathrm{E}_{49.57}$ peptide (RAHYNIVTF) were used as E7 tetramer (E7 Tm). For dead cell exclusion, 7-aminoactinomycin D (7-AAD; Invitrogen), Zombie Aqua (Biolegend) and Zombie NIR (Biolegend) were used. Interferon-regulatory factors (IRF)-1 Rabbit mAb clone: D5E4 and Phospho-NF-kB p65 clone Ser536 (Cell Signaling Technology, USA). For intracellular cytokine staining, single cell suspensions of spleens or tumors were plated in 96-well cell culture flat-bottom plates in the presence of dendritic cells preloaded with SLP and brefeldin A $(4 \mu \mathrm{g} / \mathrm{mL})$. After 5 hours incubation, cells were stained for surface markers and were fixed in $0.5 \%$ paraformaldehyde overnight. To measure Tregs, eBioscience FOXP3/Transcription Factor Staining Buffer Set (Invitrogen, USA) was used. Thereafter, cells were washed, stained for cytokines and subsequently analyzed by flow cytometry. Samples were measured with a Becton Dickinson (BD) LSRII flow cytometer, and results were analyzed using FlowJo software (Tree Star).

To sort cells, single cells isolated from the digested tumors or sorted from the digested tumor for CD $45^{+}$ (immune cells) and CD45- (tumor cells) were used. To sort tumor cells, live CD45 CD $31^{-} \mathrm{CD} 90.2^{-} \mathrm{CD} 44^{+}$cells were sorted with BD FACS Aria cell sorter.

\section{Mass cytometry and data analysis}

Mass cytometry (CyTOF) staining and acquisition was performed as generally described. ${ }^{13}$ In short, single-cell suspensions of TC-1 tumors were purified by Percoll gradient to remove aggregates and debris, stained with 37 mouse immune markers, and acquired on a Helios mass cytometer (Fluidigm Sciences). The metal-conjugated antibodies are listed in online supplementary file 1. 
After manual gating of alive singlet $\mathrm{CD} 45^{+}$cells using FlowJo, non-supervised clustering was performed by H-SNE analysis with default parameters using Cytosplore software. ${ }^{14}$ After clustering was performed based on all markers, cell types were manually assigned to clusters using the following criteria: $\mathrm{CD} 8^{+} \mathrm{T}$ cells $\left(\mathrm{CD}^{+} \mathrm{CD} 8 \mathrm{a}^{+}\right)$, $\mathrm{CD}^{+} \mathrm{T}$ cells $\left(\mathrm{CD}^{+}{ }^{+} \mathrm{CD} 8 \mathrm{a}\right)$, inflammatory myeloid cells $\left(\mathrm{CD} 11 \mathrm{~b}^{+} \mathrm{Ly} 6 \mathrm{C}^{\mathrm{hi}} \mathrm{F} 4 / 80^{\text {low }}\right)$, tumor-associated macrophages $\left(\mathrm{CD} 11 \mathrm{~b}^{+} \mathrm{F} 4 / 80^{\text {hi }} \mathrm{Ly}_{6 \mathrm{C}^{\mathrm{low}}}\right)$, neutrophils $\left(\mathrm{CD} 11 \mathrm{~b}^{+} \mathrm{Ly}_{6 \mathrm{G}^{+}}\right)$, eosinophils $\left(\mathrm{CD} 11 \mathrm{~b}^{+}\right.$Siglec- $\left.\mathrm{F}^{+}\right)$and plasmacytoid dendritic cells (pDCs; Siglec-H ${ }^{+}$BST2 $^{+}$B220 ${ }^{+}$).

\section{RNAseq analysis}

RNA was isolated with the NucleoSpin RNA XS kit (Macherey-Nagel, Düren, Germany). RNA-sequencing library preparation including ribosomal RNA depletion and sequencing were performed at GenomeScan B.V. (Leiden The Netherlands). At least 50 million, paired-end, $150 \mathrm{bp}$ reads were generated per sample. These were mapped against the mouse reference genome (mm10 build) using GSnap. ${ }^{15}$ Read counts were generated per gene using htseq-count. Trimmed mean of M-values normalization was preformed using edgeR R package. ${ }^{16}$ Genes with overall low expression were filtered out, by only selecting genes with at last 0.7 counts per million in at least three samples. For comparisons between groups we selected genes included in the hallmarks of cancer pathways. ${ }^{17}$ Limma-Voom was used for statistical analysis. ${ }^{18}$ Genes were considered as significantly differentially expressed with a false discovery rate below 0.05 . Pathway analysis of the hallmarks of cancer pathways was performed using the Ensemble of Gene Set Enrichment Analysis (EGSEA) R package that combines the results of several pathway analysis methods. ${ }^{19}$

\section{Patient samples}

Formalin-fixed paraffin-embedded biopsies of 24 HPV16 ${ }^{+}$ vulvar high-grade squamous intraepithelial lesions (vHSIL) patients, treated with an experimental vaccine containing 13 SLPs covering the entire amino acid sequence of HPV16 oncoproteins E6 and E7, were cut in 4 um thick sections. These samples were stained with two multiplex immunofluorescence panels, ${ }^{20}$ one for T cells and one for myeloid cells. The slides were then scanned with the Vectra multispectral imaging system (PerkinElmer), and cells were, after manual training, automatically phenotyped and counted with inForm advanced image analysis software (PerkinElmer).

\section{Immunohistochemistry}

A $4 \mu \mathrm{m}$ section of formalin-fixed, paraffin-embedded tumor tissue was mounted on adhesive slides. Following deparaffinization and rehydration, endogenous peroxidase activity was blocked with a $0,3 \%$ hydrogen peroxidase/methanol solution (Merck Millipore, Burlington, Massachusetts, USA) for $20 \mathrm{~min}$. Microwave-mediated antigen retrieval was performed in $10 \mathrm{mM}$ citrate $(\mathrm{pH}$ 6.0) buffer for $10 \mathrm{~min}$. For TGF $\beta$, slides were incubated with normal goat serum (1:10, DAKO Agilent Technologies, USA). For CD3, slides were incubated with SuperBlock (PBS) blocking buffer (Thermo Scientific). The slides were incubated for $30 \mathrm{~min}$ to reduce non-specific binding of the primary antibody. Murine anti-TGF $\beta$ clone TB21 (1:800, Anogen-Yes Biotech Laboratories, Canada), rabbit anti- $\beta$-catenin clone D10A8 (1:100, Cell Signaling Technology, USA) and rabbit antihuman CD3e clone D7A6E (1:200, Cell Signaling Technology, USA) were diluted in PBS/1\% BSA and applied overnight For $\beta$-catenin, HRP-labeled, swine antirabbit immunoglobulins (DAKO Agilent technologies) were used to bind $\beta$-catenin antibody while poly-HRP labeled, goat antimouse/ rabbit IgG was applied for TGF $\beta$ immunodetection. For CD3, following washing in PBS $/ 0,05 \%$ Tween, slides were incubated for $60 \mathrm{~min}$ with biotinylated goat anti-rabbit, IgG (1:200, Aligent, USA). Next, VECTASTAIN Elite ABC-HRP Kit, Peroxidase (standard) (Vectorlabs, USA) was used to label the biotinylated goat antirabbit, IgG. Antibody binding was detected with $\mathrm{DAB}+$ chromogen (DAKO, Agilent Technologies, USA) after which nuclear counterstaining was done using haematoxylin (Thermo Fisher Scientific, USA).

TGF $\beta$ expression was mostly present in the tumor stroma at the rim of the tumors. Differential TGF $\beta$ intensities in the rim of the tumors were analyzed by the Image Management Systems 3.3.1 (PHILIPS) by measuring the percentage of the tumor rim expressing TGF $\beta$ compared the to the total perimeter of the tumor, The expression was normalized to the negative control (no primary antibody) for each tumor. $\beta$-catenin expression was detected in both tumor and stromal cells and, furthermore, could display cytoplasmic or nuclear localization. Therefore, tumor and stromal compartments were scored separately and intracellular localization was also noted. Staining intensity was differentiated into 0 (negative), 1 (weak), 2 (positive) and 3 (strong).

\section{qPCR analysis}

RNA was isolated from the cells with an RNeasy kit (Qiagen) according to manufacturer's protocol. Isolated RNA was quantified with Nanodrop (Thermo Scientific). Transformation of RNA into cDNA was performed with a high capacity RNA-to-cDNA kit (Applied Biosystems). cDNA (5-10 ng per well) was analyzed by SYBR green real-time PCR with $10 \mathrm{nM}$ primers using a CFX96 or CFX384 Real-Time System C1000 Thermal Cycler (Bio$\mathrm{Rad})$. The primers used for qPCR are shown in the table below. To measure the chemokine and chemokine receptors, mouse chemokines and receptors RT2 Profiler PCR Array Mouse Chemokines and receptors was purchased from Qiagen (online supplementary file 2).

\section{CTL assay}

Naïve C57BL/6 mice were vaccinated with SLP vaccines as described above on day 0 and 14. Splenocytes were isolated 8 days after the last vaccination and restimulated in vitro with dendritic cells (DCs) loaded with SLP or 
irradiated TC-1 tumor cells. After restimulation, splenocytes were harvested by using ethylenediaminetetraacetic acid (EDTA) and CD8 T cells were isolated by using the mouse $\mathrm{CD}^{+} \mathrm{T}$ lymphocyte enrichment set (BD Biosciences) and used as effector cells. Tumor cells isolated from the untreated or relapsed tumor-bearing mice were exposed to IFN $\gamma$ (10 IU, Prospec) 1 day before CTL assay and were use as target cells. Target cells were labeled with $100 \mu \mathrm{L}^{51} \mathrm{Cr}$ for 1 hour, washed and plated into a 96-well round-bottom plate at a density of 2.000 tumor cells/ well with different ratios of effector cells. After 4 hours incubation, supernatants of the cells were harvested and the percentage of ${ }^{51} \mathrm{Cr}$ release was measured by a gamma counter.

\section{TGF $\beta$ and IL-6 measurements}

TGF $\beta$ and IL- 6 were measured in the supernatants of tumor cells. In brief, digested tumors were seeded in 96-flat bottom plate. After overnight, the supernatants were collected and stored at $-80^{\circ} \mathrm{C}$ until measurement. Total TGF $\beta$ levels were determined using commercially available DuoSet ELISAs (R\&D systems, USA) after acidification of the samples to activate latent TGF $\beta$ as described before. ${ }^{21}{ }^{22}$ IL- 6 was measured using a mouse Bio-Plex Pro Mouse Cytokine 23-plex immunoassay (BioRad, Herculus, California, USA) according to manufacturer's protocol.

\section{Statistical analysis}

Statistical analyzes were performed using Prism (GraphPad). Survival data were analyzed by Kaplan-Meier and log-rank (Mantel-Cox) tests. Statistical significance was determined using the Mann-Whitney test or unpaired t-test as described in the figure legends, depending on the parametricity of the data. Two-sided $p$ values $\leq 0.05$ were considered statistically significant.

\section{RESULTS \\ Non-curative immunotherapy drives the development of immune-resistant tumors}

Vaccination with the HPV16 E7 ${ }_{43-77}$ SLP, containing both a CTL epitope and a helper T (Th) epitope, and CpG resulted in a strong $\mathrm{T}$-cell response and the full eradication of almost all established TC-1 tumors in mice receiving tailbase vaccination, hereby reaching draining lymph nodes at both flanks (optimal vaccine condition) (figure 1A and online supplementary file $3 \mathrm{~A}, \mathrm{~B})$. In contrast, vaccination in the contralateral flank (suboptimal vaccine condition) - resulting in a lower E7-specific T-cell responsestill induced tumor regression in all mice between days 16 and 22 but from day 28 onwards the tumors recurred (figure 1B and online supplementary file 3A-C). Amplification of the tumor-specific T-cell response by booster vaccination at day 22 could not prevent tumor recurrence (figure 1B-D). This was not due to the incapacity of tumor-bearing animals to respond to this booster vaccination as the magnitude of circulating tumor-specific
(E7)-specific $\mathrm{CD} 8^{+}$and $\mathrm{CD} 8^{+} \mathrm{CD} 127^{+} \mathrm{KLRG}^{+}{ }^{+}$effector T cells increased in blood (figure 1D and online supplementary file 3D-E). In addition, splenic and lymph node-derived T cells were fully capable to produce IFN $\gamma$, tumor necrosis factor (TNF) and IL-2 after E7 stimulation (figure $1 \mathrm{E}$ and online supplementary file 4A,B). Moreover, the numbers of splenic $\mathrm{CD}_{4}^{+} \mathrm{IFN} \gamma$, TNF and IL-2 producing $\mathrm{T}$ cells were increased after booster vaccination (figure $1 \mathrm{~F}$ and online supplementary file $4 \mathrm{C}, \mathrm{D}$ ). Thus, a suboptimal vaccine-induced tumor-specific T-cell response fosters therapy resistance. Since the suboptimal vaccine condition clearly mimics the clinical situation, it provides an excellent model to study acquired resistance to immunotherapy.

\section{Classical immune escape mechanisms do not play a role in tumor recurrence}

Loss of tumor antigen or major histocompatibility complex (MHC) I expression can mediate immune resistance. ${ }^{23}{ }^{24}$ However, all the relapsed tumors retained the expression of $\mathrm{E} 7$ and $\mathrm{H} 2-\mathrm{Db}$, which presents the $\mathrm{E} 7_{49-57}$ T-cell epitope, at comparable levels to the TC-1 tumor cell line and tumor cells isolated from both untreated and relapsed tumors were efficiently killed by $\mathrm{CD}^{+} \mathrm{T}$ cells isolated from vaccinated mice but not by $\mathrm{T}$ cells isolated from non-vaccinated mice (online supplementary file $5 \mathrm{~A}-\mathrm{C})$.

Another obvious immune escape mechanism is formed by the PD-L1/PD-1 inhibitory pathway. ${ }^{25}{ }^{26}$ Vaccination of TC-1 tumor-bearing mice resulted in a strong increase in the number of intratumoral leukocytes including $\mathrm{CD} 8^{+}$ $\mathrm{T}$ cells and myeloid cells. ${ }^{27}$ Among these leucocytes, the number of highly activated, type 1 cytokine-producing $\mathrm{CD}^{+} \mathrm{T}$ cells expressing several coinhibitory molecules increased (online supplementary file 5D-F). This coincided with a lower percentage of TC-1 tumor cells expressing the proliferation marker Ki-67 (online supplementary file $5 \mathrm{G}$ ) suggesting that the $\mathrm{T}$ cells still exert their function. Comparison of PD-1, TIM-3 and LAG-3 expression on $\mathrm{CD}^{+} \mathrm{T}$ cells including tumor-specific $\mathrm{T}$ cells revealed that almost all intratumoral $\mathrm{CD}^{+} \mathrm{T}$ cells $(\sim 90 \%-$ $100 \%$ ) expressed PD-1 both at the start of the regression and at the time of recurrence (online supplementary file $6 \mathrm{~A}, \mathrm{~B})$. We previously demonstrated that blockade of NKG2A did not prevent TC-1 recurrences. ${ }^{28}$ PD-L1 and PD-L2 levels were not increased on recurrent tumor cells but intratumoral myeloid cells showed high PD-L1 expression during tumor regression, which may facilitate the subsequent relapse (online supplementary file 6C,D). Nevertheless, recurrence could not be prevented by using PD-1 or PD-L1 blocking antibodies either before or at the time of regression (online supplementary file $6 \mathrm{E}, \mathrm{F}$ ).

\section{Vaccine-resistant recurrent tumors display impaired $\mathrm{CD8}^{+} \mathrm{T}$ cell infiltration}

Most likely, tumor cells deployed other means to escape the immune response. Therefore, we quantified the different subsets of immune cells in the tumor 
A

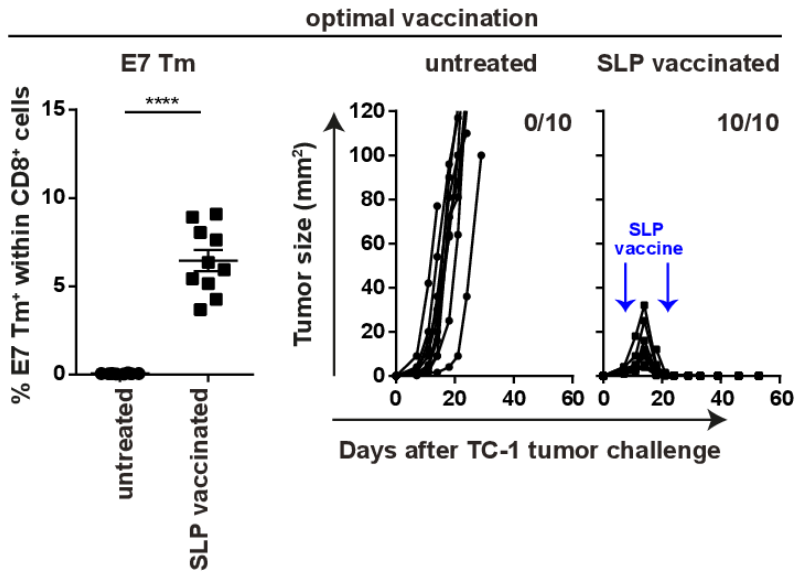

C

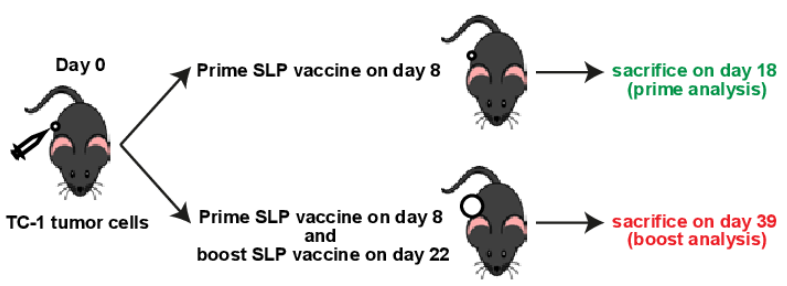

E

spleen

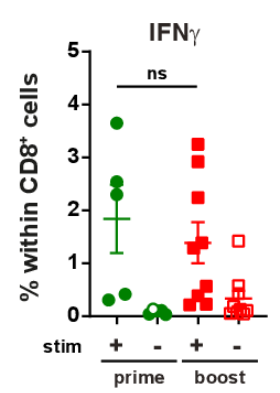

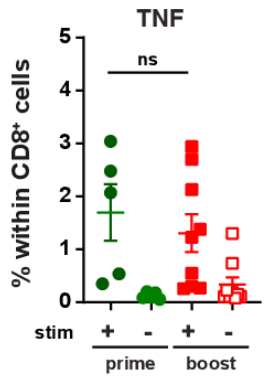

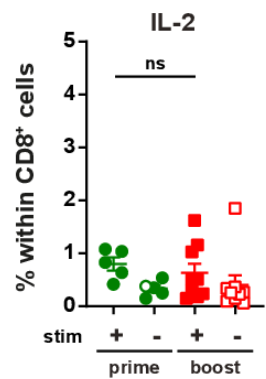

B

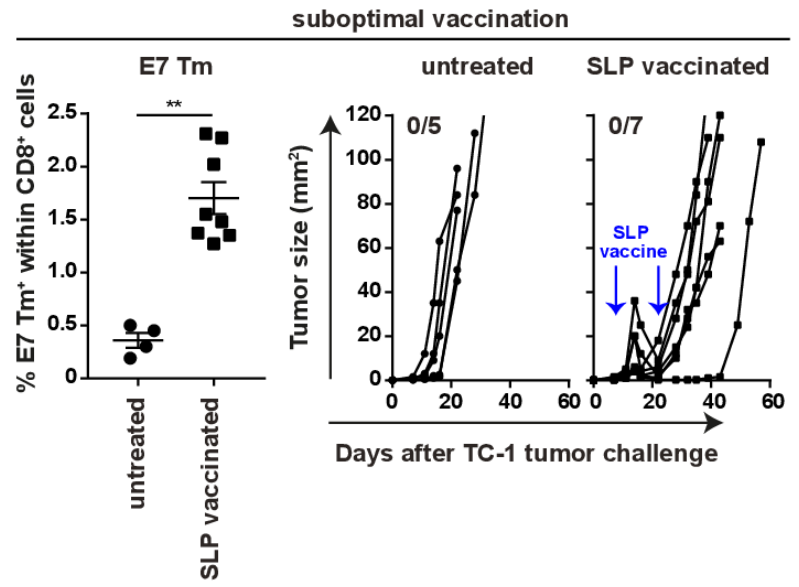

D
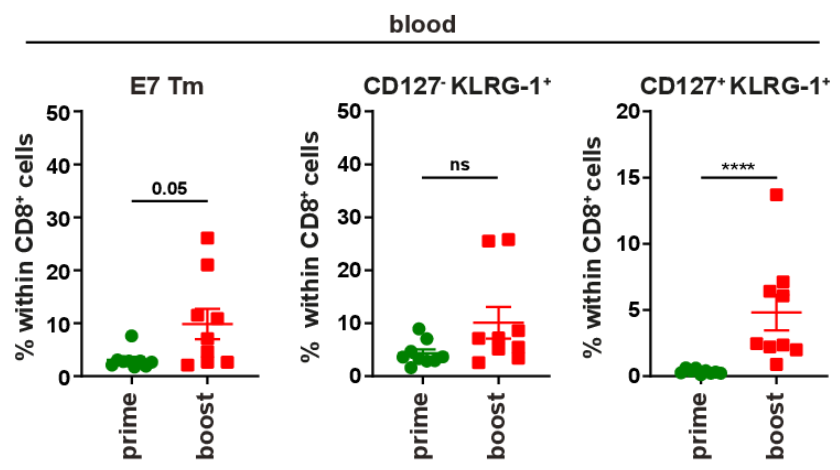

F

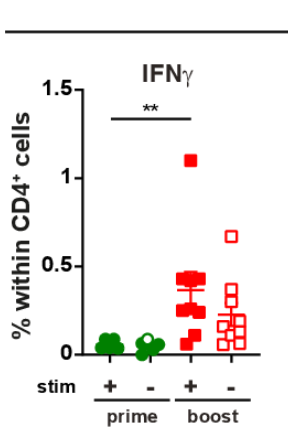

spleen

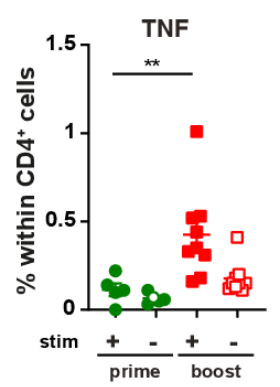

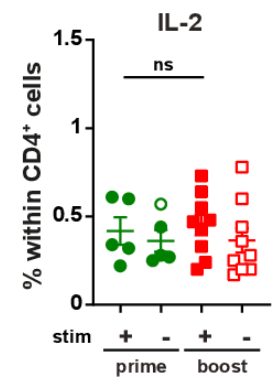

Figure 1 Booster vaccination amplifies the E7-specific response but does not prevent relapse. Mice were injected with TC-1 tumor cells on day 0 and vaccinated with prime and boost SLP vaccine on day 8 and 22 subcutaneously in tail base (optimal vaccination) (A) or contralateral flank (suboptimal vaccination) (B). Percentage of E7 $\mathrm{Tm}^{+}$cells within $C D 8^{+}$cells and tumor outgrowth of untreated mice and SLP vaccinated mice that received the vaccination in optimal (A) or suboptimal (B) vaccination. (C) The scheme of the experiment shown in D-F. (D) The percentage of E7 Tm ${ }^{+}, \mathrm{CD} 127^{-} \mathrm{KLRG}-1^{+}, \mathrm{CD} 127^{+} \mathrm{KLRG}-1^{+} \mathrm{CD} 8^{+}$ T cells in blood at day 16 (prime analysis) and day 36 (boost analysis). (E, F) The percentage of IFN $\gamma^{+}$, $\mathrm{TNF}^{+}$and IL-2 ${ }^{+}$cells within $C D 8^{+} T$ cells $(E)$ or $C D 4^{+} T$ cells $(F)$ in spleen. Data presented in $A, B, D-F$ are mean $\pm S E M$, and statistical analysis was performed using Mann-Whitney U test. ${ }^{*} \mathrm{P}<0.05 ;{ }^{* \star} \mathrm{P}<0.01$; ${ }^{* * *} \mathrm{P}<0.001$; ${ }^{* \star *} \mathrm{P}<0.0001$. IFN $\gamma$, interferon- $\gamma$, IL-2, interleukin 2; ns, not significant; TNF, tumor necrosis factor.

microenvironment at the time of tumor regression (day 18 ) or relapse (day 39), when there was no overt difference in the sizes of regressing and relapsed tumors (online supplementary file 7A-C). Overall leucocyte infiltration was strongly reduced and altered in composition in the relapsed tumor leading to a near absence of $\mathrm{CD} 8^{+} \mathrm{T}$ cells, including E7-specific CD8 ${ }^{+} \mathrm{T}$ cells (online supplementary file 8A). The percentage of $\mathrm{CD} 4^{+} \mathrm{T}$ cells and Tregs, both present in low quantities among the tumor infiltrating immune cells, was not altered (online supplementary file $8 \mathrm{C})$. Interestingly, the cytokine production of the intratumoral $\mathrm{CD}^{+} \mathrm{T}$ cells in the recurrent tumors, although present at much lower numbers, was similar to that of the $\mathrm{CD}^{+} \mathrm{T}$ cells in regressing tumors while the percentage of type 1 cytokine-producing $\mathrm{CD} 4^{+} \mathrm{T}$ cells was increased (online supplementary file 8D). The significantly lower presence of $\mathrm{CD}^{+} \mathrm{T}$ cells in recurrent tumors could reflect a lower capacity of tumors to attract these $\mathrm{T}$ cells 
and/or a failure of the $\mathrm{T}$ cells to proliferate and expand locally. To explore potential defects in the attraction of $\mathrm{T}$ cells to the tumor, the RNA expression of 84 chemokines and chemokine receptors from all cells present in the tumors from non-treated, regressed and recurrent tumors was measured (online supplementary file 9). This showed that $\mathrm{T}$ cell-attracting chemokines, including CXCL9, were among the abundantly expressed cytokines in regressing tumors but absent in recurrent tumors. In addition, the expression of its receptor CXCR3 appeared lower on the relapsed tumor-infiltrating $\mathrm{CD}^{+} \mathrm{T}$ cells, although not significant (online supplementary file 10A). However, antibody-mediated blocking of CXCR3 delayed the onset of tumor regression but did not negatively influence overall survival of the mice (online supplementary file 10B, C), indicating that CXCL9 was not absolutely required. As we previously showed that tumor cells can produce several chemokines after activation by IFN $\gamma$-producing tumor-infiltrating T cells, ${ }^{27}{ }^{29}$ the lower expression of chemokines in relapsed tumors most likely is a reflection of reduced numbers of tumor-infiltrating immune cells and not the cause for immune escape. Indeed, TC-1 tumor cells from relapsed tumors were still responsive to stimulation in vitro with IFN $\gamma$ and TNF and produced several cytokines (online supplementary file 10D) indicating that these signaling pathways were still intact. In addition, the capacity of the intratumoral $\mathrm{T}$ cells to locally expand was assessed by their expression of Ki-67 showing that the percentage of $\mathrm{CD}^{+} \mathrm{T}$ cells expressing Ki-67 is lower in recurrent than in regressing tumors (online supplementary file $8 \mathrm{~B}$ ). To overcome this problem, we aimed to amplify the T-cell costimulatory signals OX40 or $4-1 \mathrm{BB}^{30-32}$ by administration of agonistic antibodies at the time of regression. This did not prevent tumor recurrence or improve the survival of vaccinated mice, and further addition of PD-1 blockade had no effect (online supplementary file 11A-C).

\section{Escaped tumors display a changed transcriptome}

Next, we investigated the alterations in cancer cells using RNA sequencing on flow cytometry sorted fractions of cancer cells derived from untreated and relapsed tumors. Gene Set Enrichment Analysis of the Hallmark gene set collection ${ }^{17}$ showed differential expression of 160 of the 2086 genes analyzed between untreated and relapsed samples. Top 100 differentially expressed genes are shown in online supplementary file 12. In the relapsed tumors, strong upregulation of epithelial-mesenchymal transition (EMT) genes and downregulation in the TNF and p53 pathways was observed (figure 2A,B; online supplementary file 13). It has been extensively shown that several signaling pathways, including TGF- $\beta$ and Wnt/ $\beta$-catenin, play a role in EMT, ${ }^{334}$ hence we confirmed the transcriptome data at the protein level. While the expression of cytoplasmic and nuclear $\beta$-catenin was about twofold higher in the stroma of recurrent tumors (online supplementary file 14A), the expression of TGF- $\beta$ was strongly increased in a layer of cells-presumably fibroblasts—surrounding the tumor (figure 2C) and increased quantities of TGF- $\beta$ were measured in the supernatant of ex vivo recurrent tumors (figure 2D). In accordance with the down regulation of the p53 pathway, the expression levels of $m d m 2$, ccng1, ei24 and pidd were lower in recurrent tumors (figure 2E). Recently, TGF- $\beta$ production and signaling in fibroblasts was shown to restrict T-cell infiltration of tumors,${ }^{35}$ however, administration of TGF- $\beta$-blocking antibodies from the regression phase onwards did not prevent tumor recurrence or altered survival (figure $2 \mathrm{~F}$ and online supplementary file 14B). Similarly, activation of p53 signaling by using the MDM2 small-molecule antagonist RG7112 alone or in combination with TGF- $\beta$ blocking antibody had no effect (figure 2G and online supplementary file 14C). Altogether, these data show that tumor cells had become differently wired as a consequence of a non-curative T-cell attack, but the changes in the TGF- $\beta$ and p53 pathways were not the underlying cause for therapy resistance.

\section{Non-responsiveness relates to impaired inflammatory myeloid cell infiltration in mice and man}

Cure of TC-1-bearing mice requires the influx of tumorspecific $\mathrm{CD}^{+} \mathrm{T}$ cells and that of matured (MHC class $\mathrm{II}^{+}$) inflammatory (Ly6C ${ }^{\text {hi }}$ ) phagocytic myeloid cells, ${ }^{2737}$ which kill tumor cells by TNF and phagocyte them. ${ }^{38}$ Whereas the percentage of myeloid cells was unaltered between regressed and relapsed tumors, the composition of these intratumoral cells, comprizing inflammatory $\left(\right.$ Ly6C $\left.^{\text {high }}\right)$ MHC class $\mathrm{II}^{+}$myeloid cells, tumor associated macrophages (Ly6C ${ }^{\text {low }}$ cells) and neutrophils $\left(\mathrm{Ly}_{6} \mathrm{G}^{+}\right)$, was changed in favor of the non-inflammatory Ly6 $\mathrm{C}^{\text {low- }}$ $\mathrm{F} 4 / 80^{\text {hi/low }}$ cells (figure $3 \mathrm{~A}-\mathrm{C}$ and online supplementary file 15A), and coincided with higher levels of IL-6 (online supplementary file 15B), both of which may foster local immune suppression. To test this, we depleted Ly6C $\mathrm{C}^{\text {low }}$ cells using the CSF1R inhibitor PLX3397 (PLX) from day 20,4 days after the start of regression on day 16. As expected, ${ }^{27}$ this depleted intratumoral but not splenic macrophages and had no effect on the vaccine-induced $\mathrm{CD}^{+}$T-cell response (online supplementary file 15C,D) . However, neither PLX (online supplementary file 15E,F), nor blockade of IL-6 in combination with TGF- $\beta$ blocking antibodies (online supplementary file $15 \mathrm{G}, \mathrm{H}$ ) had an effect on tumor recurrence. This not only showed that the Ly6C ${ }^{\text {low }}$ myeloid cell population was not required for recurrence, but also implied that the inflammatory myeloid cell population, known to assist tumor killing and to be affected by PLX treatment, ${ }^{27}$ was not present. Thus, it appeared that acquired resistance was associated with a lack of inflammatory myeloid cell infiltration. To validate these findings in the human setting, we analyzed the immune microenvironment of patients with HPV16induced vHSIL, after their systemic HPV16-specific T-cell response had been amplified by HPV16 SLP vaccination $(\mathrm{n}=24) .{ }^{20}$ Interestingly, clinical responders (defined as $\geq 50 \%$ lesion regression 12 months after vaccination) displayed significantly higher infiltration 
A

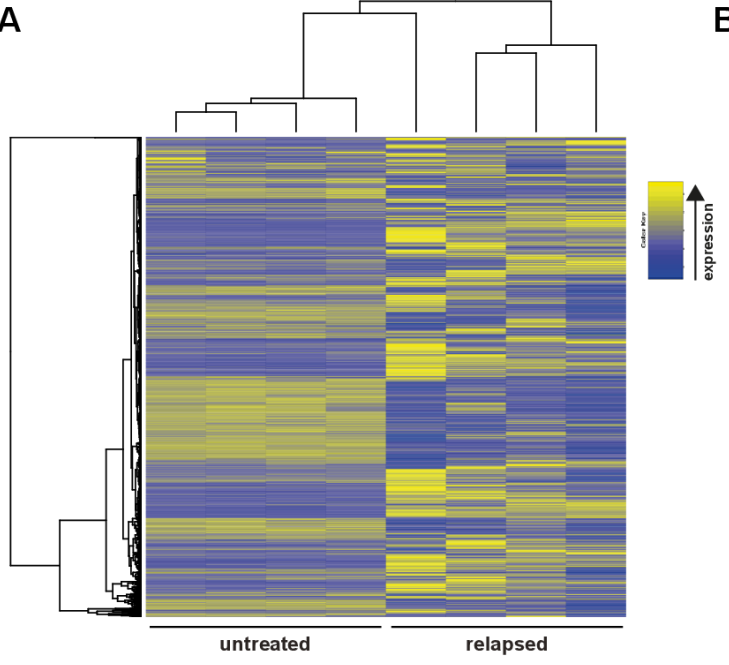

C

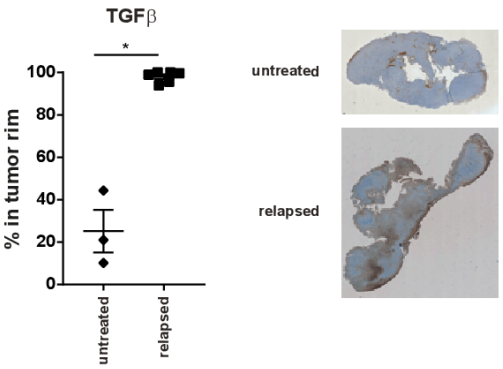

B

D
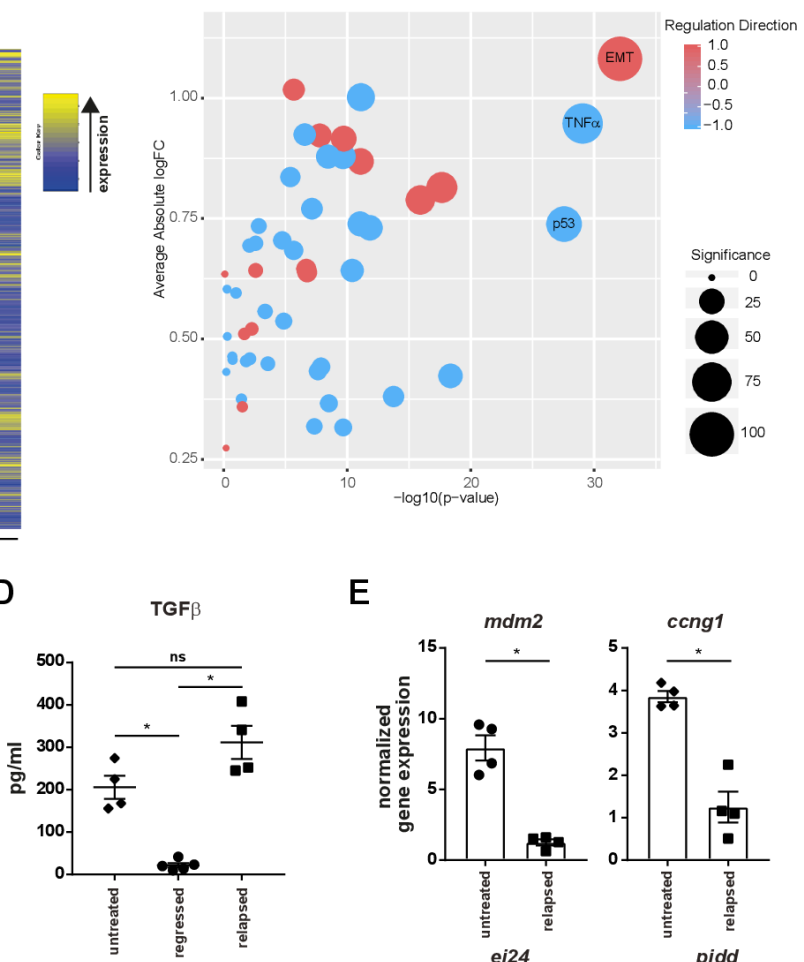

E
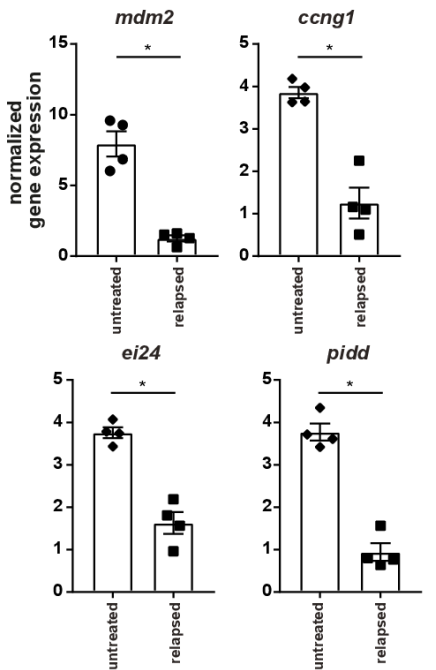

F

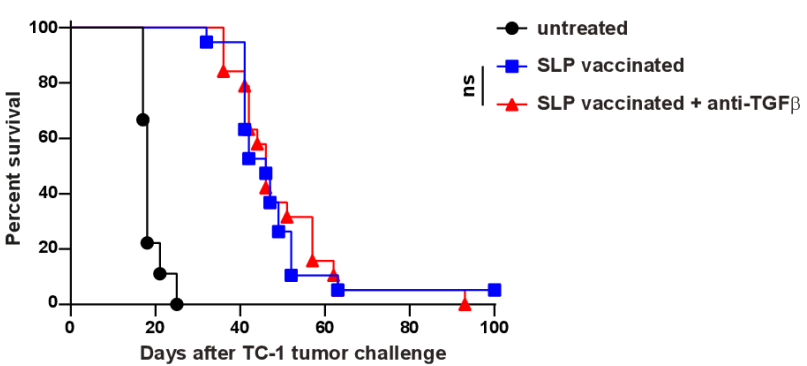

G

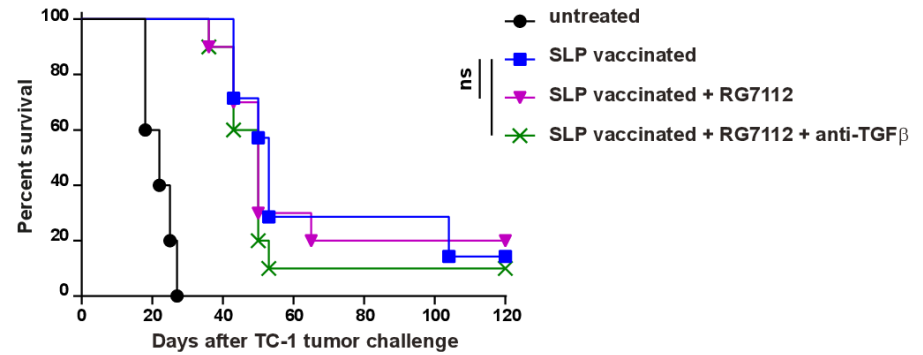

Figure 2 Local recurrences display an altered transcriptome. (A-E) mice were injected with TC-1 tumor cells on day 0 . Then, mice were vaccinated with prime SLP suboptimal vaccine on day 8 (regressed) or kept untreated (untreated) and were sacrificed on day 18. Another group of mice vaccinated with prime and boost SLP suboptimal vaccine on day 8 and 22 were sacrificed at the time of relapse on day 39 (relapsed). (A, B) RNA seq and gene set enrichment analysis of tumor cells sorted from untreated tumor-bearing mice (day 18) or mice with relapsed tumors (day 39). (C) TGF $\beta$ score of the rim of the tumor microenvironment from untreated and relapsed tumor-bearing mice. (D) Measurement of TGF $\beta$ production by ELISA from the cells present in the tumor microenvironment of the untreated mice or SLP suboptimal vaccinated mice at the time of the regression (day 18) or relapse (day 39). (E) RNA expression of $m d m 2$, ccng1, ei24 and pidd genes by qPCR from tumor cells sorted from untreated mice (day 18) or SLP suboptimal vaccinated mice at the time of the relapse (day 39). (F-G) Survival of the mice treated with prime and boost SLP suboptimal vaccination alone or in combination with TGF $\beta$-blocking antibody (F) and/or RG7112 (G). Mice were injected with TC-1 tumor cells on day 0 . Then, mice were vaccinated with prime and boost SLP suboptimal vaccine on day 8 and 22. TGF $\beta$ neutralizing antibody and RG7112 were administered from day 20 till 32 as described in methods. data presented in $\mathrm{C}-\mathrm{E}$ are mean $\pm \mathrm{SEM}$, and statistical analysis was performed using Mann-Whitney $\mathrm{U}$ test. statistical analysis shown in $\mathrm{G}$ and $\mathrm{F}$ is determined by a log-rank (Mantel-Cox) test. ${ }^{*} \mathrm{P}<0.05$. ns, not significant; TGF $\beta$, transforming growth factor- $\beta$. 
A
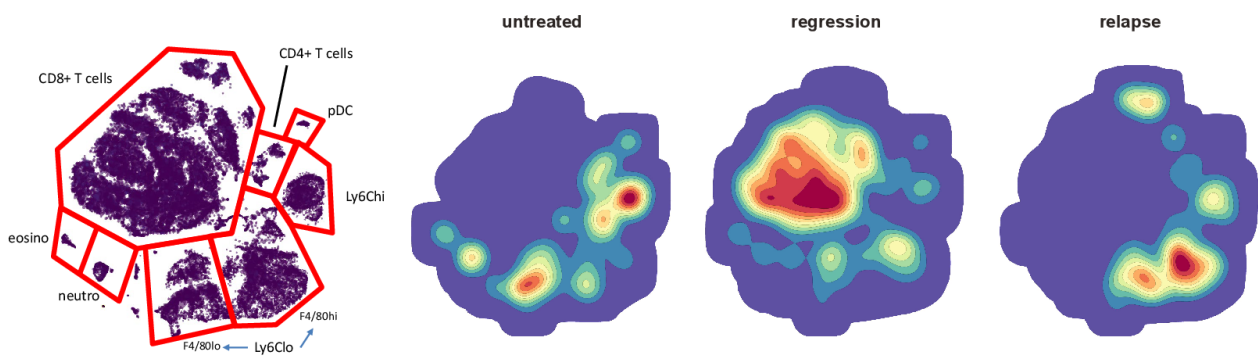

B

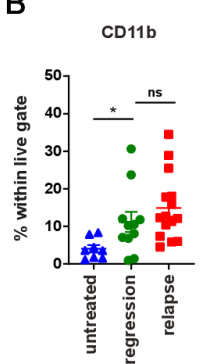

C
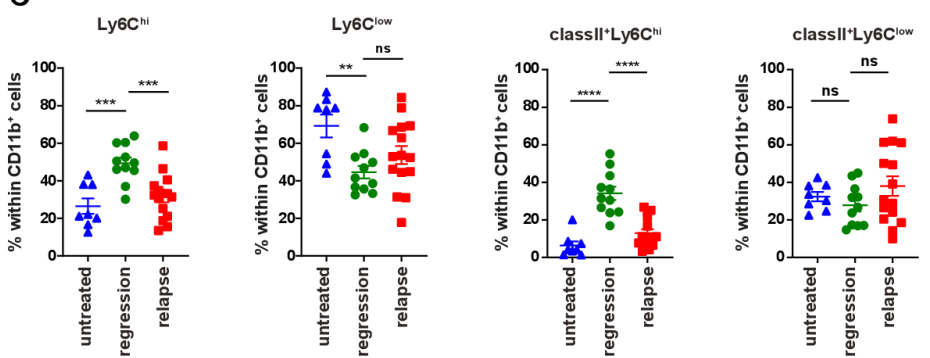

D

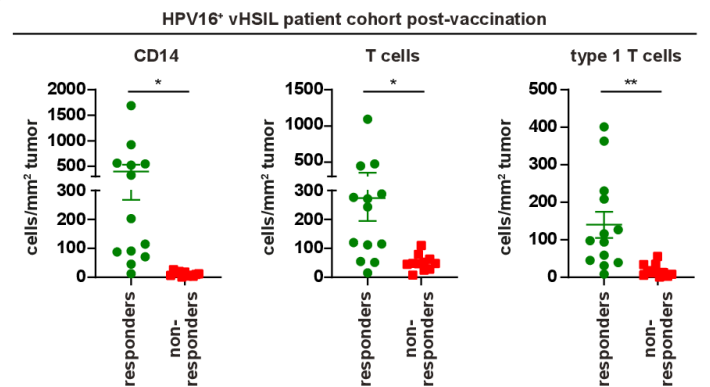

Figure 3 Response to vaccine is correlated with infiltration of inflammatory myeloid cells. Mice were injected with TC-1 tumor cells on day 0 . Then, mice were vaccinated with prime SLP suboptimal vaccine on day 8 (regressed) or kept untreated (untreated) and were sacrificed on day 18. Another group of mice vaccinated with prime and boost SLP suboptimal vaccine on day 8 and 22 were sacrificed at the time of relapse on day 39 (relapsed). (A) H-SNE plots of total CD45 immune infiltrates of TC-1 tumors of untreated, regressed or relapsed. Tumors were analyzed by mass cytometry followed by non-supervised clustering using Cytosplore as described in materials and methods. The relative contribution of major myeloid and lymphoid cell types is indicated in the H-SNE plot, as indicated. (B) The percentage of CD11 $\mathrm{b}^{+}$within live gate. (C) The percentage of

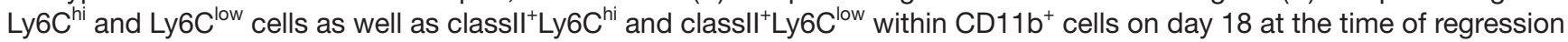
(regression) or at the time of relapse on day 39 (relapse). The scheme is shown in online supplementary file 7A. (D) Immune microenvironment of VHSIL patients 3 months after therapeutic vaccination by HPV16 SLP, separated for responders ( $n=13$ )

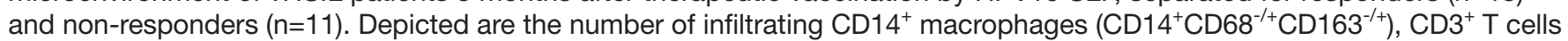
$\left(\mathrm{CD}^{+} \mathrm{CD}^{-/+} \mathrm{Foxp}^{-}\right)$and type one cytokine producing $\left(\mathrm{Tbet}^{+}\right) \mathrm{T}$ cells $\left(\mathrm{CD}^{+} \mathrm{CD}^{-/+} \mathrm{Foxp}^{-} \mathrm{Tbet}^{+}\right)$per mm ${ }^{2}$ tumor post vaccination. data presented are mean $\pm \mathrm{SEM}$, and statistical analysis was performed using unpaired t-test. ${ }^{*} \mathrm{P}<0.05 ;{ }^{* *} \mathrm{P}<0.01 ;{ }^{* * *} \mathrm{P}<0.001$; ${ }^{\star * \star \star} \mathrm{P}<0.0001$. ns, not significant; vHSIL, vulvar high-grade squamous intraepithelial lesions.

with $\mathrm{CD}_{14} 4^{+} \mathrm{CD} 68^{+/-} \mathrm{CD} 163^{-}$inflammatory macrophages after vaccination when compared with non-responders (figure 3D). This influx of CD14 $4^{+}$inflammatory macrophages coincided with significant T-cell infiltration, primarily type I cytokine-producing $\left(\right.$ Tbet $\left.^{+}\right) \mathrm{T}$ cells (figure 3D). Interestingly, several of the non-responding lesions are infiltrated with $\mathrm{T}$ cells postvaccination, but hardly with inflammatory myeloid cells. Thus, our data clearly showed that vaccine-resistance was associated with an impaired local inflammatory myeloid cell infiltration after vaccination, both in our mouse model and in patients.

\section{Secondary immune resistance is caused by a tumor cell- imprinted failure to attract myeloid effector cells}

Until now, we had investigated secondary resistance to vaccination in a setting of local recurrence, the actual cause which may be obscured due to several different biological processes such as immune cell infiltration and tumor regression, wound healing and oncogenic pathway rewiring in tumor cells, all acting in a relatively small time window and in the same anatomical location during the regrowth of tumors. To interrogate the major mechanism underlying therapy-induced secondary resistance, we tested if TC-1 tumor cells isolated at the time 
of the relapse respond to the same vaccination protocol when injected in a naive host. Flow cytometry-sorted live TC-1 tumor cells were reinjected in two groups of naive mice, one of which received the vaccine on day 8 and 22 while the other was left untreated (figure $4 \mathrm{~A}$ ). The reinjected tumor cells from untreated mice regressed on SLP vaccination, whereas reinjected recurrent tumor cells did not respond at all (figure 4B). This implied that the relapsed phenotype was imprinted into the cancer cells. Analysis of the tumor immune microenvironment at day 15 revealed that the tumors originating from reinjected recurrent tumor cells displayed a strong reduction in the number of $\mathrm{CD} 45^{+}$tumor-infiltrating immune cells (figure 4C). Remarkably, this was not due to a lack of $\mathrm{CD}^{+} \mathrm{T}$-cell infiltration as their number, type 1 cytokine production, Ki-67 expression and intratumoral distribution, was similar to what is seen in the vaccine-responsive tumors originating from TC-1 tumor cells (figure 4D-G). Instead, the numbers of tumor-infiltrating $\mathrm{CD}_{11} \mathrm{~b}^{+}$, matured (MHC class $\mathrm{II}^{+}$) and inflammatory (Ly6C ${ }^{\text {high }}$ ) myeloid cells were decreased (figure 5A). This included a decrease in $\mathrm{CD} 11 \mathrm{~b}^{+} \mathrm{F} 4 / 80^{+} \mathrm{iNos}^{+}$(M1-type) macrophages

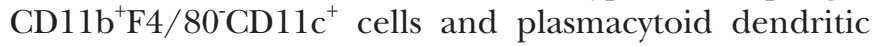
cells (pDCs) (figure 5B). In addition, the percentage

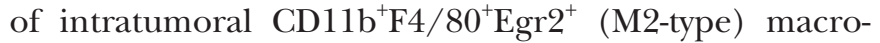
phages and $\mathrm{Ly}_{6 \mathrm{G}}{ }^{+}$neutrophils were somewhat increased in the resistant tumors (figure 5C). Consistent with this change, an overall reduction in the expression of several IRF was found in the microenvironment (online supplementary file 16A). Furthermore, the expression of IRF-1

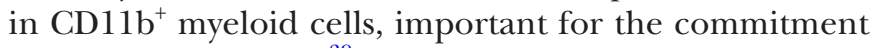
of M1 macrophages, ${ }^{39}$ was reduced (figure 5D). Moreover, in spite of the presence of similar numbers of intratumoral type 1 cytokine-producing $\mathrm{CD}^{+} \mathrm{T}$ cells, the expression level of TNF was also strongly decreased in the reinjected recurrent tumors (figure 5E), suggesting that this was produced by the myeloid effector cells and potentially explaining the observed reduction in TNFsignaling in the transcriptome of relapsed tumor cells (figure 2A,B). Thus, secondary immune resistance is not due to a lack of intratumoral functionally active $\mathrm{CD} 8^{+} \mathrm{T}$ cells but is associated with an impaired influx of inflammatory mature myeloid effector cells after vaccination.

\section{Reprogramming the microenvironment sensitizes escaped tumors to immunotherapy}

To test if a lack of tumor-infiltrating inflammatory myeloid cells facilitated vaccine resistance in this setting, we made use of cisplatin as it induces an influx of matured (MHC class $\mathrm{II}^{+}$) inflammatory (Ly6C $\mathrm{C}^{\text {hi }}$ ) phagocytic myeloid cells $^{27}{ }^{37}$ (online supplementary file 17A). Especially, the combination of cisplatin and vaccination stimulated an increased $\mathrm{CD}_{4} 5^{+}$immune cell infiltration in the reinjected TC-1 recurrent tumors. Due to an influx of CD11 b ${ }^{+}$ and $\mathrm{CD} 11 \mathrm{~b}^{-} \mathrm{CD} 11 \mathrm{c}^{+}$myeloid cells expressing MHC class II and/or Ly6C (figure 6A-F; online supplementary file 17B$\mathrm{D})$, the percentages of the inflammatory mature $\mathrm{CD}_{11} \mathrm{~b}^{+}$ myeloid cells in the reinjected TC-1 recurrent tumors reached similar levels as observed in normal TC-1 tumors after vaccination without cisplatin treatment. The level of phosphorylated $\mathrm{p} 65$, as a witness of proinflammatory NF-K $\beta$ pathway activation, was also increased in the rein-

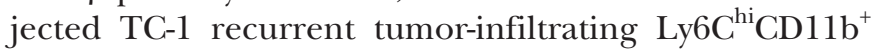
myeloid cells, to the same level as detected in these cells from normal TC-1 tumors after vaccination (figure 6G). Detailed analysis of the myeloid cell composition revealed that the combination treatment drove the influx of predominantly $\mathrm{CD} 11 \mathrm{~b}^{-} \mathrm{CD} 11 \mathrm{c}^{+}$pDCs and MHC class $\mathrm{II}^{+}$ M2-type macrophages and not $\mathrm{CD} 11 \mathrm{~b}^{-} \mathrm{CD} 11 \mathrm{c}^{+} \mathrm{MHC}$ Class$\mathrm{sII}^{+} \mathrm{CD} 103^{+}$(cDC1) and $\mathrm{CD} 11 \mathrm{~b}^{+} \mathrm{CD} 11 \mathrm{c}^{+} \mathrm{F} 4 / 80^{-}$(cDC2) (figure $6 \mathrm{H}$,I; online supplementary file $17 \mathrm{E}$ ). In addition, the combination treatment restored the percentage of tumor-resident $\left(\mathrm{Ly}_{6} \mathrm{C}^{\mathrm{low}}\right)$ matured M2-type macrophages expressing MHC class II in reinjected TC-1 recurrent tumor, to the levels seen in normal TC-1 tumors after vaccination (figure 6I). The combination treatment, but not cisplatin alone, also resulted in an increased infiltration with $\mathrm{CD}^{+}$and $\mathrm{CD} 8^{+} \mathrm{T}$ cells in TC- 1 recurrent tumors (online supplementary file $17 \mathrm{~F}$ ), the percentage of which exceeded the number of HPV-specific T cells (figure 6C). Based on the fact that cisplatin does not induce immunogenic cell death ${ }^{40}$ and did not drive overt $\mathrm{CD} 4^{+}$and $\mathrm{CD} 8^{+}$ $\mathrm{T}$ cell infiltration, it is likely that the inflamed tumors attracted many bystander $\mathrm{CD} 8+\mathrm{T}$ cells, ${ }^{41}$ these nonHPV-specific CD8+T cells are unlikely to have a major contribution to the clinical response in the combination treatment of TC-1 recurrent tumors. Finally, we analyzed if this apparent restoration of the mature and inflammatory intratumoral myeloid cell population also reinstalled the sensitivity of the reinjected TC-1 recurrent tumors to T-cell therapy. Indeed, while cisplatin only delayed tumor outgrowth, combination of cisplatin with SLP vaccination induce full tumor regression in the majority of mice (figure 7A,B), similar to what was seen with the original TC-1 tumor (figure 1B), and significantly improved the survival in reinjected TC-1 recurrent tumor-bearing mice. Thus, the major mechanism underlying secondary immune resistance after vaccination was the lack of sufficient intratumoral mature myeloid effector cells after vaccination.

\section{DISCUSSION}

In our experimental model for acquired resistance, the induction of suboptimal tumor-specific T-cell response still induces regression of growing tumors but fails to wipe out all tumor cells, leading to immune escape and tumor relapse in accordance with the principles of cancer immunoediting. ${ }^{42}$ We excluded extrinsic mechanisms known to confer primary or secondary resistance to immunotherapy, such as Tregs, suppressive macrophages, TGF- $\beta$ or IL- 6 and showed that the intratumoral $\mathrm{CD}^{+} \mathrm{T}$ cells were still functional. Moreover, we excluded a role for the well-known intrinsic mechanisms associated with tumor antigen expression, alterations in the antigen processing pathway, checkpoint expression, resistance 
A

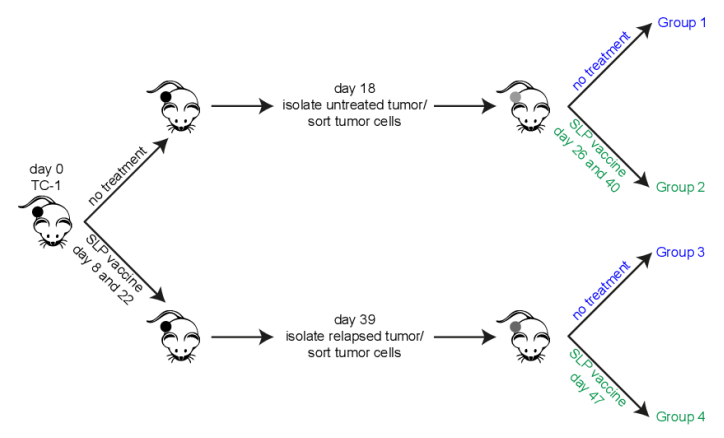

B

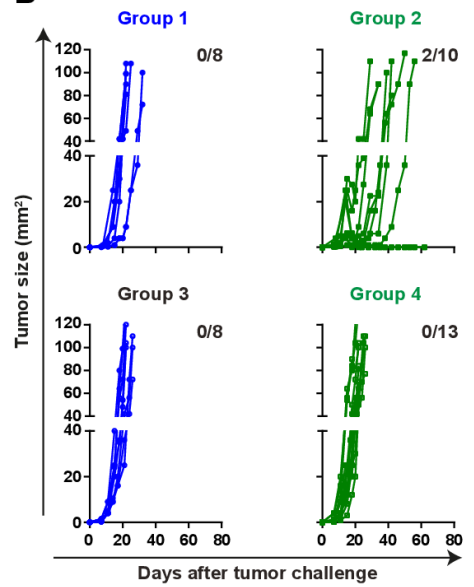

C

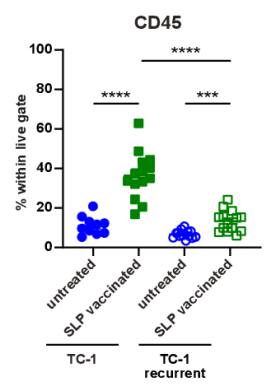

F

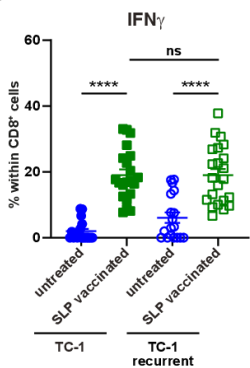

G

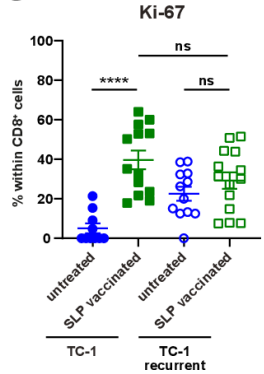

D
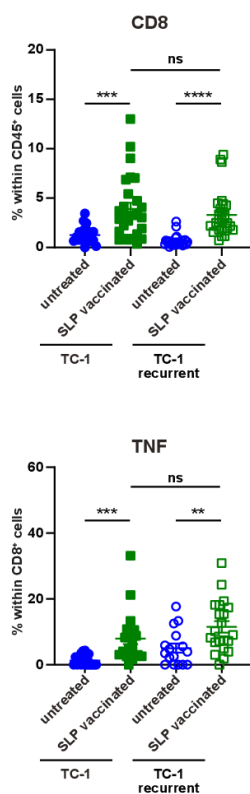

E

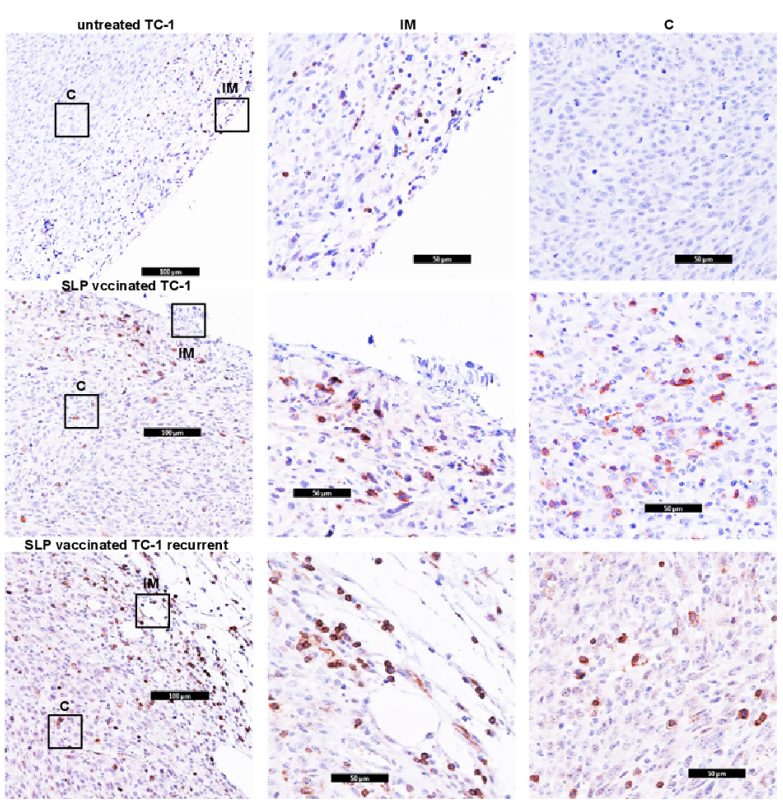

Figure 4 Non-Curative immunotherapy drives the development of immune resistant tumors. (A) Scheme of the experimental procedure. In brief, mice were injected with TC-1 tumor cells on day 0. Then, mice were suboptimal vaccinated with SLP vaccine on days 8 and 22 or kept untreated. Untreated mice were sacrificed on day 18 . Tumor cells were sorted and injected back into naïve mice. these mice received suboptimal vaccination on days 26 and 40 or kept untreated. Similarly, suboptimal vaccinated mice were sacrificed on day 39 , tumor cells were sorted and injected back into naïve mice, which were suboptimal vaccinated on days 47 or left untreated. (B) Tumor outgrowth of the mice shown in (A). The number of tumorfree mice from total is indicated. Data are pooled of two experiments. (C-G) The scheme of the experiment is shown in (A). The mice (group 1-4) were sacrificed on day 15 post tumor challenge. (C) The percentage of $C D 45^{+}$cells within live gate in the tumor microenvironment. (D) The percentage of intratumoral $C D 8^{+} T$ cells within $C D 45^{+}$cells. $(E)$ The representative immunohistochemistry images of $\mathrm{CD}^{+} \mathrm{T}$ cells in tumors of untreated TC-1, suboptimal SLP-vaccinated TC-1 and suboptimal SLP-vaccinated TC-1 recurrent tumor-bearing mice (C: center, IM: invasion margin). (F) IFN $\gamma$ and TNF production of intratumoral $\mathrm{CD}^{+} \mathrm{T}$ cells. (G) The percentage of Ki67 ${ }^{+}$intratumoral CD8 ${ }^{+} \mathrm{T}$ cells. data presented in C, D, F and $\mathrm{G}$ are mean $\pm \mathrm{SEM}$, and statistical analysis was performed using unpaired t-test. ${ }^{* \star} \mathrm{P}<0.01 ;{ }^{* * *} \mathrm{P}<0.001 ;{ }^{* \star * *} \mathrm{P}<0.0001$. IFN $\gamma$, interferon- $\gamma$, ns, not significant; TNF, tumor necrosis factor. 
A
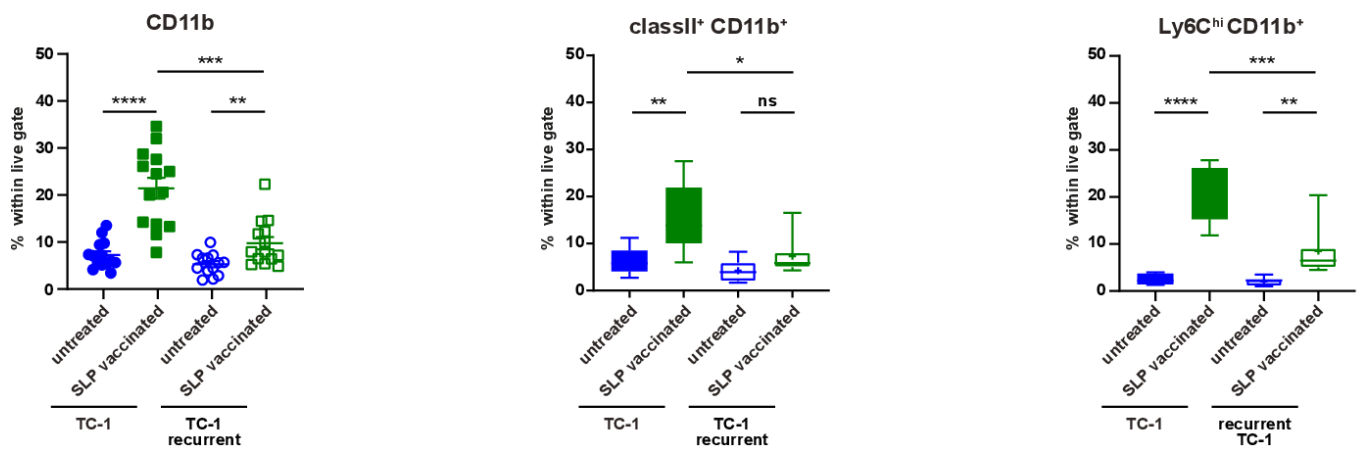

B
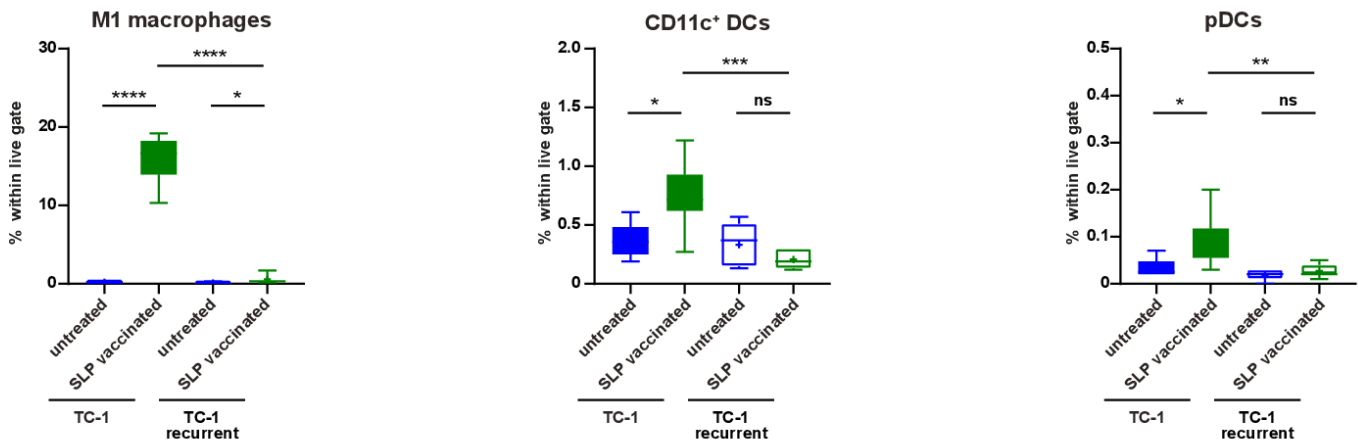

$\mathrm{C}$
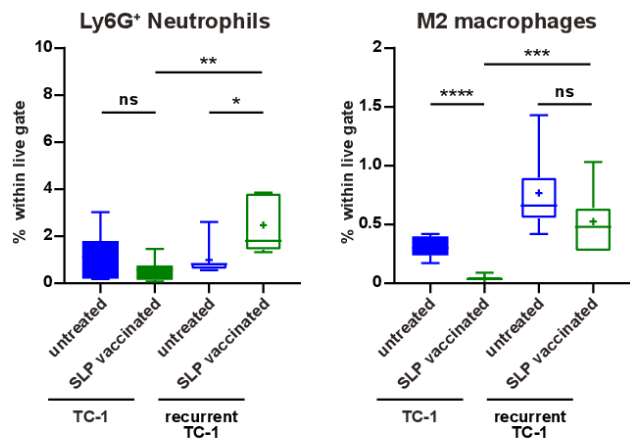

D

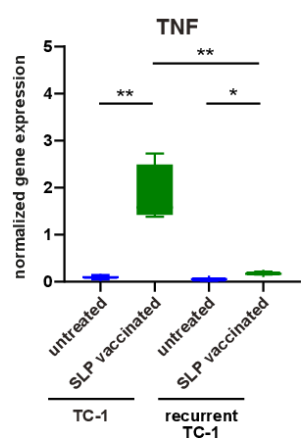

Figure 5 Recurrent tumors display impaired inflammatory myeloid cell infiltration. (A-E) The scheme of the experiment is shown in figure 4A. The mice (group 1-4) were sacrificed on day 15 post-tumor challenge. (A) The percentage of CD11 b', class $I^{+} \mathrm{CD} 11 \mathrm{~b}^{+}$and $\mathrm{Ly} 6 \mathrm{C}^{\mathrm{hi}} \mathrm{CD} 11 \mathrm{~b}^{+}$cells within live gate in the tumor microenvironment of untreated and suboptimal SLPvaccinated TC-1 and TC-1 recurrent tumor-bearing mice. (B) The percentage of M1-type macrophages, CD11 $\mathrm{C}^{+} \mathrm{DCs}$ and pDCs within live gate. (C) The percentage of intratumoral $\mathrm{Ly}_{6 \mathrm{G}}{ }^{+}$neutrophils and $\mathrm{M} 2$-type macrophages within live gate. (D) The expression level of IRF-1 on intratumoral $\mathrm{CD}_{11} \mathrm{~b}^{+}$myeloid cells. The representative histogram is shown on the right. (E) The normalized gene expression level of TNF in the tumor microenvironment of untreated and SLP-vaccinated TC-1 and TC-1 recurrent tumor-bearing mice. Data presented are mean \pm SEM in the scatter plot and min to max (mean shown as + ) in box and whiskers plots. Statistical analysis was performed using unpaired t-test. ${ }^{\star} \mathrm{P}<0.05 ;{ }^{* \star} \mathrm{P}<0.01 ;{ }^{* \star *} \mathrm{P}<0.001 ;{ }^{* \star *} \mathrm{P}<0.0001$. ns, not significant; TNF, tumor necrosis factor. 
A

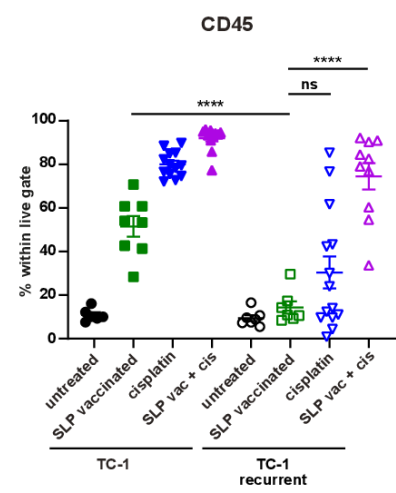

D

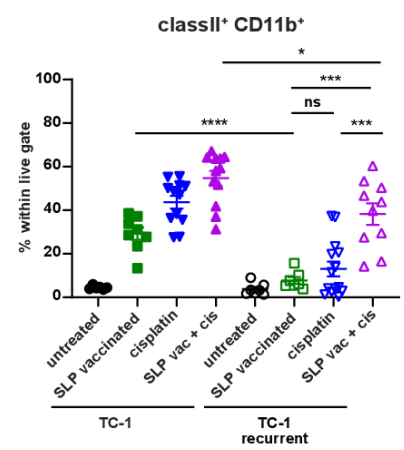

G
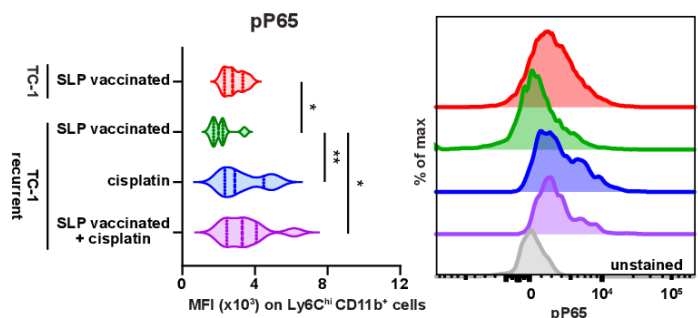

I

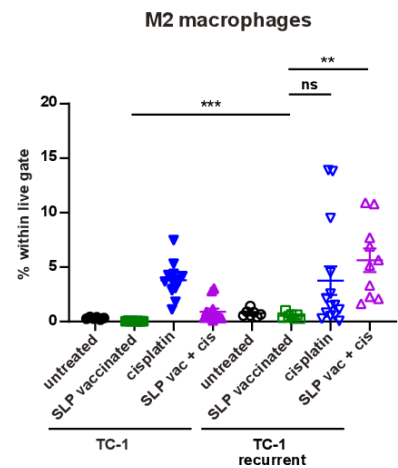

B

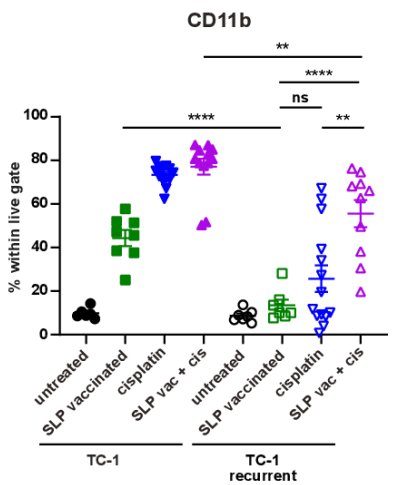

E

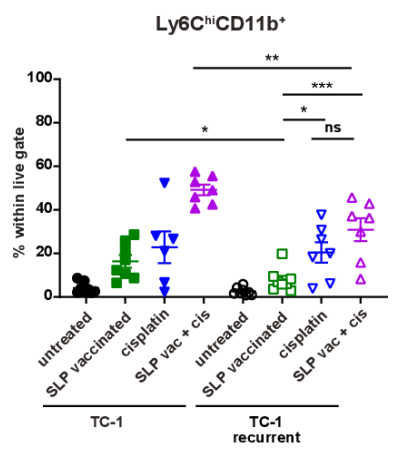

C

E7 Tm

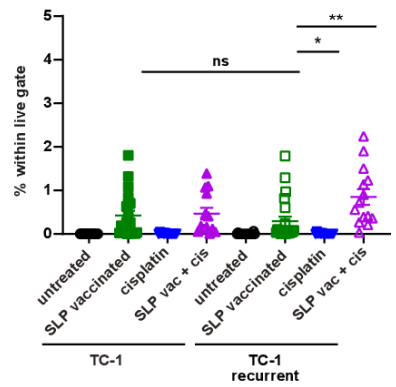

F

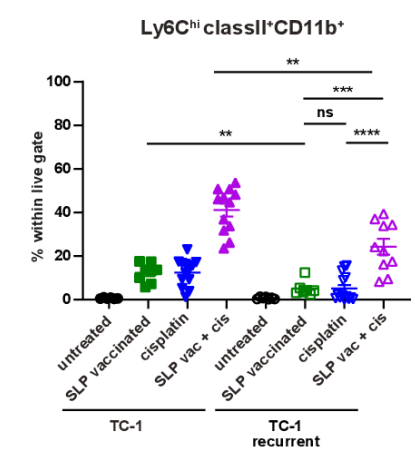

H

pDCs
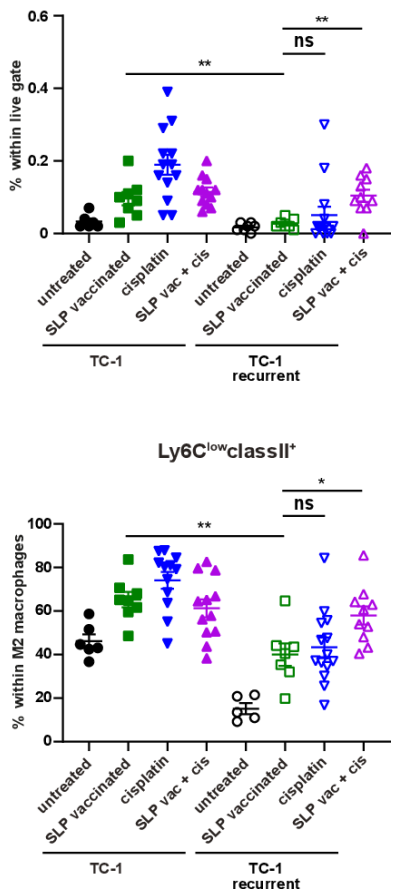

Figure 6 Reprogramming the microenvironment enhances myeloid cell infiltration. (A-I) The scheme of the experiment is shown in online supplementary file 17A. (A-F) The percentage of intratumoral CD45 ${ }^{+}$cells $(A), C D 11 b^{+}(B), E 7 \mathrm{Tm}^{+} C D 8^{+} T$ cells (C) class II ${ }^{+} C D 11 b^{+}(D)$, Ly6C $^{\text {hi }} C D 11 b^{+}(E)$ and Ly6C ${ }^{\text {hi }}$ class $I^{+} C D 11 b^{+}(F)$ within live gate of untreated, suboptimal SLP-vaccinated, cisplatin treated and combined cisplatin and suboptimal SLP-vaccination treated TC-1 and TC-1 recurrent tumor-bearing mice. (G) The expression level of pp65 on Ly6C ${ }^{\text {hi }} \mathrm{CD} 11 \mathrm{~b}^{+}$myeloid cells. The representative histogram is shown on the right. $(\mathrm{H}-\mathrm{I}) \mathrm{The}$

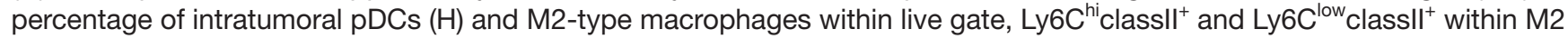
macrophages (I) of untreated, SLP-vaccinated, cisplatin treated and combined cisplatin and SLP-vaccination treated TC-1 and TC-1 recurrent tumor-bearing mice. data presented are mean \pm SEM, and statistical analysis was performed using unpaired $t-$ test. ${ }^{\star} \mathrm{P}<0.05 ;{ }^{* \star} \mathrm{P}<0.01 ;{ }^{* \star *} \mathrm{P}<0.001 ;{ }^{* \star \star *} \mathrm{P}<0.0001$. ns, not significant. 
A
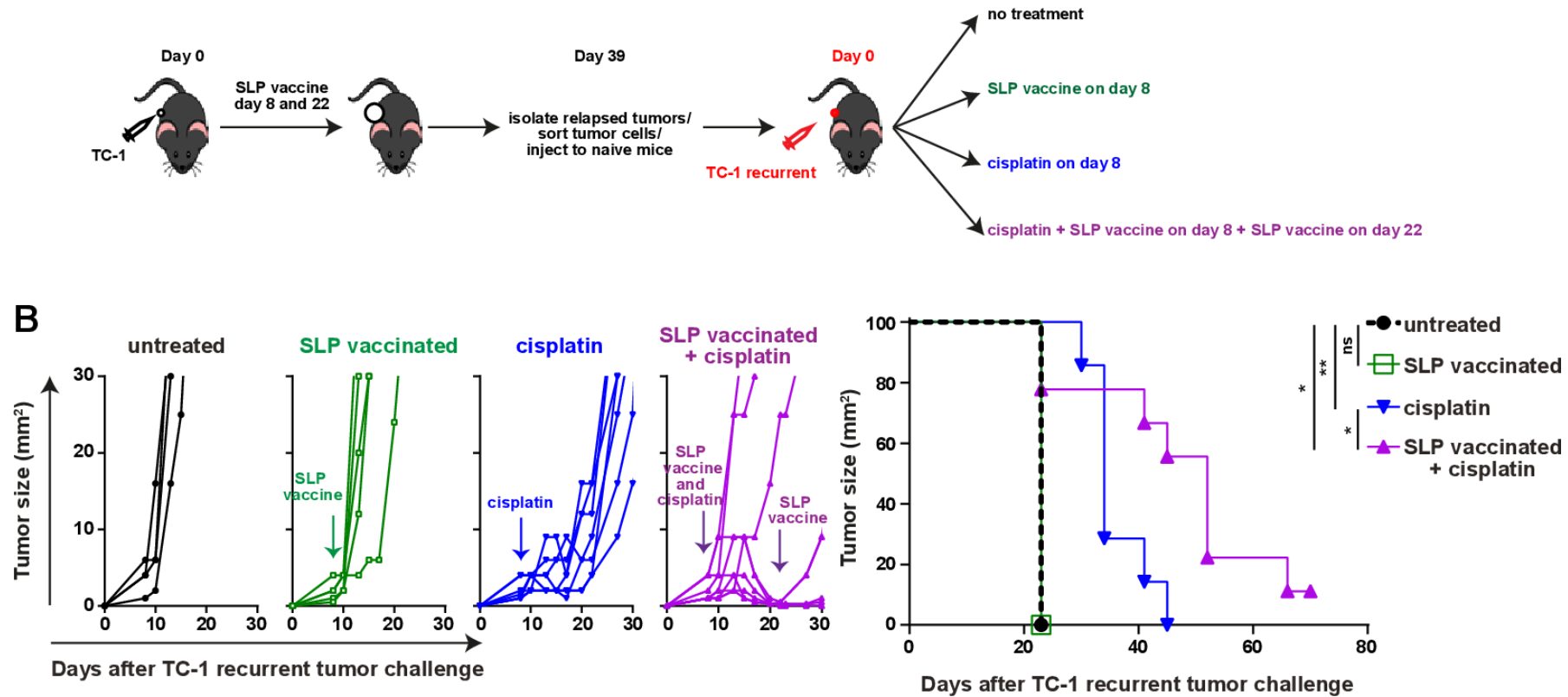

Figure 7 Reprogramming the microenvironment overcomes acquired resistance. (A) Scheme of the experiment. In brief, mice were injected with TC-1 tumor cells on day 0 and suboptimal vaccinated with SLP vaccine on days 8 and 22 . when the tumor relapsed on day 39, mice were sacrificed and tumors were harvested and tumor cells were isolated. sorted tumor cells (TC-1 recurrent) were injected into naïve mice and treated with SLP vaccine, cisplatin, the combination or kept untreated. (B) Tumor outgrowth and survival of the mice as shown in (A). Differences in survival was determined by a log-rank (Mantel-Cox) test. ${ }^{\star} \mathrm{P}<0.05 ;{ }^{\star \star} \mathrm{P}<0.01 ;$. ns, not significant.

to killing or to IFN $\gamma$ and TNF-signaling, all of which are required for activated $\mathrm{CD}^{+} \mathrm{T}$ cells to exert their antitumor function. The lowered $\mathrm{CD}^{+} \mathrm{T}$ cell infiltration observed in relapsed tumors did not form the underlying mechanism for escape, as reinjection of escaped tumor cells into naïve mice revealed that these tumors were still therapy resistant despite a strong influx with functionally active $\mathrm{CD}^{+} \mathrm{T}$ cells. Instead, the escape mechanism fostering resistance to immunotherapy was associated with a tumor cell imprinted incapacity to attract matured MHC class $\mathrm{II}^{+}$myeloid cells, in particular intratumoral pDCs, and macrophages, which was observed both during relapse and in the reinjected escape tumors. Although we are unable to pinpoint the molecular signal of this deficit at this time, potentially because it may involve an altered cross talk between cancer and stromal cells, our data show that reinstating intratumoral inflammation restored their influx and sensitized escaped tumors to vaccine-induced tumor regression. This newly identified acquired immune escape mechanism may play a role in many types of tumors, because not only the immunotherapy-mediated control of TC-1 tumors ${ }^{27} 38$ but also that of YUMMER1.7 and B16/F10 melanoma, ${ }^{43} 44$ CT26 colon cancer, 4T1 breast carcinoma and mSCC1 squamous cell carcinoma ${ }^{45}$ requires the presence of $\mathrm{CD}^{+} \mathrm{T}$ cells and inflammatory matured MHC class $\mathrm{II}^{+}$ myeloid cells. Similarly, a combination of tumor-specific $\mathrm{T}$ cells and inflammatory MHC class $\mathrm{II}^{+}$macrophages is required to prevent the development of hepatocellular cancer in mice. ${ }^{46}$ The requirement of both cell types in the tumor microenvironment fits well with the concept of programmed cell removal. This process is known to regulate cancer cell survival and is a key step in the removal of cells undergoing programmed cell death, executed by phagocytic innate cells. ${ }^{47}$ It can be envisioned that the tumor-specific CD8+T cells deliver the first hit which is then complemented by inflammatory myeloid effector cells, as they possess in vivo phagocytic functions. ${ }^{38} 45$ Additionally, myeloid effector cells may aid in this process via their production of TNF and nitric oxide, which also delivers a cytotoxic hit to tumor cells. ${ }^{3844} 45$ The influx of M2 rather than M1 macrophages in the reinjected cisplatin plus vaccine treated tumors does not contradict this concept, as M2 macrophages alike to their M1 counterparts can phagocytose cancer cells, although at a lower rate. ${ }^{48}$ Our study outcomes are also relevant for human cancers, the clinical outcome of which often is better when they are infiltrated with type 1 cytokineproducing $\mathrm{T}$ cells and myeloid cells. ${ }^{49}$ This includes HPV16-driven cervical cancer. ${ }^{50}$ Indeed, we observed that the regression of HPV16-induced pre-malignant lesions after therapeutic vaccination is associated with the influx of both $\mathrm{T}$ cells and inflammatory $\left(\mathrm{CD} 14^{+}\right)$ myeloid cells. Although T cells infiltrated the lesions of clinical non-responders at lower numbers than in clinical responders, the numbers of inflammatory myeloid cells remained very low. The absence of a coordinated $\mathrm{CD}^{+}$ $\mathrm{T}$ cell and inflammatory myeloid cell infiltration was also found to act as primary resistance mechanism in patients with HPV16-induced premalignant lesions. ${ }^{20}$ 
In conclusion, we propose that loss of the capacity to attract innate myeloid effector cells into the tumor microenvironment is a mechanism leading to primary or secondary therapy-resistance. The recognition that also tumor-infiltrating myeloid cells are required for tumor regression during immunotherapy asks for a reappraisal of their tumoricidal and phagocytic activities and new studies on how to harness this.

Acknowledgements The authors thank LJAC Hawinkels from the department of Gastroenterology and Hepatology, Leiden University Medical Center, Leiden, The Netherland for his input on the TGF $\beta$ measurement. The authors appreciate the help of Guillaume Beyrend from the Immunohematology and Blood Transfusion department at Leiden University Medical Center, Leiden, The Netherland for mass cytometry panel design and analysis.

Contributors Conception and design: EBN, TVH, RA and SHvdB. Experiments in mice: EBN, CL, MJvE, JWK, TCvdS and SvD. Collection and analyses of human materials: ZA and SHvdB. Molecular and transcriptomic analyses: AFAST, AGJ, J0 and NFCCdM. Mass cytometry: EBN, CL, ZA, MJvE, JWK, TCvdS, SvD, AFAST, AGJ, JO, NFCCdM, TVH, RA and SHvdB. Immunohistochemistry: CL, ER, NFCCdM. Flow cytometry: EBN, CL and MJvE. Analysis and interpretation of data: EBN, CL, ZA, MJvE, JWK, TCvdS, AGJ, JO, NFCCdM, TVH, RA and SHvdB. Writing, review, and/ or revision of the manuscript: EBN, TVH, RA and SHvdB. Study supervision: TVH, RA and SHvdB.

Funding This work was supported by grant 2015-7824 from the Dutch Cancer Society (SHvdB, TVH and RA) and a Biomedical Sciences Plus PhD grant from Leiden University Medical Center (EBN).

Competing interests None declared.

Patient consent for publication Not required.

Ethics approval All animal experiments were approved by the Animal Experiments Committee of LUMC and were executed according to the animal experimentation guidelines of LUMC in compliance with the guidelines of Dutch and European committees.

\section{Provenance and peer review Not commissioned; externally peer reviewed.}

Data availability statement Data are available on reasonable request.

Open access This is an open access article distributed in accordance with the Creative Commons Attribution Non Commercial (CC BY-NC 4.0) license, which permits others to distribute, remix, adapt, build upon this work non-commercially, and license their derivative works on different terms, provided the original work is properly cited, appropriate credit is given, any changes made indicated, and the use is non-commercial. See http://creativecommons.org/licenses/by-nc/4.0/.

\section{ORCID iDs}

Elham Beyranvand Nejad http://orcid.org/0000-0002-9801-1351

Ziena Abdulrahman http://orcid.org/0000-0001-9079-0293

Jan Willem Kleinovink http://orcid.org/0000-0002-4198-2077

Noel F C C de Miranda http://orcid.org/0000-0001-6122-1024

Thorbald Van Hall http://orcid.org/0000-0002-9115-558X

Ramon Arens http://orcid.org/0000-0001-5058-4110

Sjoerd H van der Burg http://orcid.org/0000-0002-6556-0354

\section{REFERENCES}

1 Ascierto PA, Del Vecchio M, Robert C, et al. Ipilimumab 10 mg/ $\mathrm{kg}$ versus ipilimumab $3 \mathrm{mg} / \mathrm{kg}$ in patients with unresectable or metastatic melanoma: a randomised, double-blind, multicentre, phase 3 trial. Lancet Oncol 2017;18:611-22.

2 Hodi FS, Chiarion-Sileni V, Gonzalez R, et al. Nivolumab plus ipilimumab or nivolumab alone versus ipilimumab alone in advanced melanoma (CheckMate 067): 4-year outcomes of a multicentre, randomised, phase 3 trial. Lancet Oncol 2018;19:1480-92.

3 Massarelli E, William W, Johnson F, et al. Combining immune checkpoint blockade and tumor-specific vaccine for patients with incurable human papillomavirus 16-related cancer: a phase 2 clinica trial. JAMA Oncol 2019;5:67-73.

4 Melief CJM, Welters MJP, Vergote I, et al. Strong vaccine responses during chemotherapy are associated with prolonged cancer survival. Sci Transl Med 2020;12:eaaz8235.
5 Mellman I, Coukos G, Dranoff G. Cancer immunotherapy comes of age. Nature 2011;480:480-9.

6 van der Burg SH, Arens R, Ossendorp F, et al. Vaccines for established cancer: overcoming the challenges posed by immune evasion. Nat Rev Cancer 2016;16:219-33.

7 Weber JS, D'Angelo SP, Minor D, et al. Nivolumab versus chemotherapy in patients with advanced melanoma who progressed after anti-CTLA-4 treatment (CheckMate 037): a randomised, controlled, open-label, phase 3 trial. Lancet Oncol 2015;16:375-84.

8 Sharma P, Hu-Lieskovan S, Wargo JA, et al. Primary, adaptive, and acquired resistance to cancer immunotherapy. Cell 2017;168:707-23.

9 Schreiber RD, Old LJ, Smyth MJ. Cancer immunoediting: integrating immunity's roles in cancer suppression and promotion. Science 2011;331:1565-70.

10 van der Sluis TC, van Duikeren S, Huppelschoten S, et al. Vaccineinduced tumor necrosis factor-producing $T$ cells synergize with cisplatin to promote tumor cell death. Clin Cancer Res 2015;21:781-94.

11 Zwaveling S, Ferreira Mota SC, Nouta J, et al. Established human papillomavirus type 16-expressing tumors are effectively eradicated following vaccination with long peptides. J Immunol 2002;169:350-8.

12 Lin KY, Guarnieri FG, Staveley-O'Carroll KF, et al. Treatment of established tumors with a novel vaccine that enhances major histocompatibility class II presentation of tumor antigen. Cancer Res 1996;56:21-6.

13 Santegoets SJ, van Ham VJ, Ehsan I, et al. The anatomical location shapes the immune infiltrate in tumors of same etiology and affects survival. Clin Cancer Res 2019;25:240-52.

14 Unen van V, Hollt T, Pezzotti N, et al. Visual analysis of mass cytometry data by hierarchical stochastic neighbour embedding reveals rare cell types. Nat Commun 2017:8:1740.

15 Wu TD, Reeder J, Lawrence M, et al. Gmap and GSNAP for genomic sequence alignment: enhancements to speed, accuracy, and functionality. Methods Mol Biol 2016;1418:283-334.

16 Robinson MD, McCarthy DJ, Smyth GK. edgeR: a Bioconductor package for differential expression analysis of digital gene expression data. Bioinformatics 2010;26:139-40.

17 Liberzon A, Birger C, Thorvaldsdóttir $\mathrm{H}$, et al. The molecular signatures database (MSigDB) hallmark gene set collection. Cell Syst 2015;1:417-25

18 Ritchie ME, Phipson B, Wu D, et al. limma powers differential expression analyses for RNA-sequencing and microarray studies. Nucleic Acids Res 2015;43:e47.

19 Alhamdoosh $\mathrm{M}, \mathrm{Ng} \mathrm{M}$, Wilson $\mathrm{NJ}$, et al. Combining multiple tools outperforms individual methods in gene set enrichment analyses. Bioinformatics 2017:33:414-24.

20 Abdulrahman Z, de Miranda N, van Esch EMG, et al. Preexisting inflammatory immune microenvironment predicts the clinical response of vulvar high-grade squamous intraepithelial lesions to therapeutic HPV16 vaccination. J Immunother Cancer 2020;8:e000563.

21 Hawinkels LJAC, Verspaget HW, van der Reijden JJ, et al. Active TGF-beta1 correlates with myofibroblasts and malignancy in the colorectal adenoma-carcinoma sequence. Cancer Sci 2009; 100:663-70.

22 Hawinkels LJAC, Verspaget HW, van Duijn W, et al. Tissue level, activation and cellular localisation of TGF-beta1 and association with survival in gastric cancer patients. Br J Cancer 2007;97:398-404.

23 DuPage M, Cheung AF, Mazumdar C, et al. Endogenous T cell responses to antigens expressed in lung adenocarcinomas delay malignant tumor progression. Cancer Cell 2011;19:72-85.

24 Matsushita H, Vesely MD, Koboldt DC, et al. Cancer exome analysis reveals a T-cell-dependent mechanism of cancer immunoediting. Nature 2012;482:400-4.

25 Iwai Y, Ishida M, Tanaka Y, et al. Involvement of PD-L1 on tumor cells in the escape from host immune system and tumor immunotherapy by PD-L1 blockade. Proc Natl Acad Sci U S A 2002;99:12293-7.

26 Latchman Y, Wood CR, Chernova T, et al. PD-L2 is a second ligand for PD-1 and inhibits T cell activation. Nat Immunol 2001;2:261-8.

27 van der Sluis TC, Sluijter M, van Duikeren S, et al. Therapeutic peptide vaccine-induced CD8 T cells strongly modulate intratumoral macrophages required for tumor regression. Cancer Immunol Res 2015;3:1042-51.

28 van Montfoort N, Borst L, Korrer MJ, et al. NKG2A Blockade Potentiates CD8 T Cell Immunity Induced by Cancer Vaccines. Cell 2018:175:1744-55.

29 Doorduijn EM, Sluijter M, Salvatori DC, et al. CD4 + T Cell and NK Cell Interplay Key to Regression of MHC Class I low Tumors upon TLR7/8 Agonist Therapy. Cancer Immunol Res 2017;5:642-53.

30 Croft M. Control of immunity by the TNFR-related molecule OX40 (CD134). Annu Rev Immunol 2010;28:57-78. 
31 Oh HS, Choi BK, Kim YH, et al. 4-1Bb signaling enhances primary and secondary population expansion of CD8+ T cells by maximizing autocrine IL-2/IL-2 receptor signaling. PLoS One 2015;10:e0126765.

32 Othman AS, Franke-Fayard BM, Imai T, et al. Ox40 stimulation enhances protective immune responses induced after vaccination with attenuated malaria parasites. Front Cell Infect Microbiol 2018;8:247.

33 Gonzalez DM, Medici D. Signaling mechanisms of the epithelialmesenchymal transition. Sci Signal 2014;7:re8.

34 Lamouille S, Xu J, Derynck R. Molecular mechanisms of epithelialmesenchymal transition. Nat Rev Mol Cell Biol 2014;15:178-96.

35 Mariathasan S, Turley SJ, Nickles D, et al. Tgf $\beta$ attenuates tumour response to PD-L1 blockade by contributing to exclusion of T cells. Nature 2018;554:544-8.

36 Tauriello DVF, Palomo-Ponce S, Stork D, et al. Tgf $\beta$ drives immune evasion in genetically reconstituted colon cancer metastasis. Nature 2018;554:538-43.

37 Beyranvand Nejad E, van der Sluis TC, van Duikeren S, et al. Tumor eradication by cisplatin is sustained by CD80/86-Mediated costimulation of CD8+ T cells. Cancer Res 2016;76:6017-29.

38 Thoreau M, Penny HL, Tan K, et al. Vaccine-induced tumor regression requires a dynamic cooperation between $\mathrm{T}$ cells and myeloid cells at the tumor site. Oncotarget 2015;6:27832-46.

39 Chistiakov DA, Myasoedova VA, Revin VV, et al. The impact of interferon-regulatory factors to macrophage differentiation and polarization into M1 and M2. Immunobiology 2018;223:101-11.

40 Martins I, Kepp O, Schlemmer F, et al. Restoration of the immunogenicity of cisplatin-induced cancer cell death by endoplasmic reticulum stress. Oncogene 2011;30:1147-58.

41 Simoni Y, Becht E, Fehlings M, et al. Bystander CD8+ T cells are abundant and phenotypically distinct in human tumour infiltrates. Nature 2018;557:575-9.
42 Mittal D, Gubin MM, Schreiber RD, et al. New insights into cancer immunoediting and its three component phases-elimination, equilibrium and escape. Curr Opin Immunol 2014;27:16-25.

43 Etzerodt A, Tsalkitzi K, Maniecki M, et al. Specific targeting of CD163+ TAMs mobilizes inflammatory monocytes and promotes T cell-mediated tumor regression. J Exp Med 2019;216:2394-411.

44 zhao J, Zhang Z, Xue Y, et al. Anti-tumor macrophages activated by ferumoxytol combined or surface-functionalized with the TLR3 agonist poly $(\mathrm{I}: \mathrm{C})$ promote melanoma regression. Theranostics 2018;8:6307-21.

45 Ohkuri T, Kosaka A, Ishibashi K, et al. Intratumoral administration of cGAMP transiently accumulates potent macrophages for anti-tumor immunity at a mouse tumor site. Cancer Immunol Immunother 2017;66:705-16.

46 Kang T-W, Yevsa T, Woller N, et al. Senescence surveillance of pre-malignant hepatocytes limits liver cancer development. Nature 2011;479:547-51.

47 Chao MP, Majeti R, Weissman IL. Programmed cell removal: a new obstacle in the road to developing cancer. Nat Rev Cancer 2012;12:58-67.

48 Zhang M, Hutter G, Kahn SA, et al. Anti-CD47 treatment stimulates phagocytosis of glioblastoma by $\mathrm{M} 1$ and $\mathrm{M} 2$ polarized macrophages and promotes M1 polarized macrophages in vivo. PLoS One 2016;11:e0153550.

49 Fridman WH, Zitvogel L, Sautès-Fridman C, et al. The immune contexture in cancer prognosis and treatment. Nat Rev Clin Oncol 2017;14:717-34.

50 de Vos van Steenwijk PJ, Ramwadhdoebe TH, Goedemans R, et al. Tumor-infiltrating CD14-positive myeloid cells and CD8-positive T-cells prolong survival in patients with cervical carcinoma. Int $J$ Cancer 2013;133:2884-94. 